Prepared in cooperation with New Mexico Game and Fish and Texas Parks and Wildlife Department

\title{
Lesser Prairie-Chicken Nest Site Selection, Microclimate, and Nest Survival in Association with Vegetation Responses to a Grassland Restoration Program
}

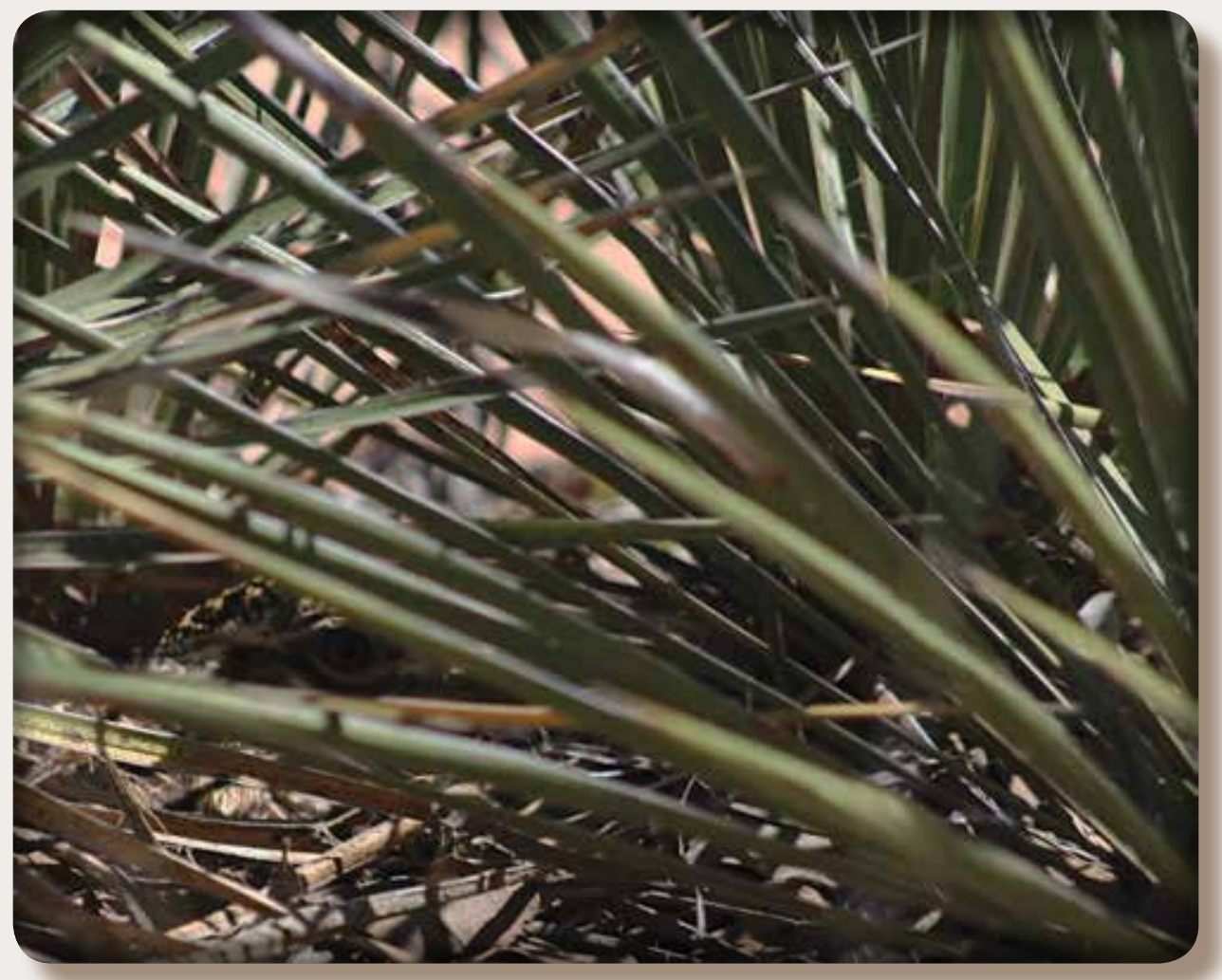

Open-File Report 2013-1235 
Cover photograph, Lesser prairie-chicken incubating eggs. 


\section{Lesser Prairie-Chicken Nest Site Selection, Microclimate, and Nest Survival in Association with Vegetation Responses to a Grassland Restoration Program}

By Clint W. Boal, Blake A. Grisham, David A. Haukos, Jennifer C. Zavaleta, and Charles Dixon

Prepared in cooperation with New Mexico Game and Fish and Texas Parks and Wildlife Department

Open-File Report 2013-1235 


\section{U.S. Department of the Interior \\ SALLY JEWELL, Secretary}

\section{U.S. Geological Survey \\ Suzette M. Kimball, Acting Director}

\section{U.S. Geological Survey, Reston, Virginia: 2014}

For more information on the USGS — the Federal source for science about the Earth, its natural and living resources, natural hazards, and the environment, visit http://www.usgs.gov or call 1-888-ASK-USGS.

For an overview of USGS information products, including maps, imagery, and publications, visit http://www.usgs.gov/pubprod

To order this and other USGS information products, visit http://store.usgs.gov

Any use of trade, firm, or product names is for descriptive purposes only and does not imply endorsement by the U.S. Government.

Although this information product, for the most part, is in the public domain, it also may contain copyrighted materials as noted in the text. Permission to reproduce copyrighted items must be secured from the copyright owner.

Suggested citation:

Boal, C.W., Grisham, B.G., Haukos, D.A., Zavaleta, J.C., and Dixon, Charles, 2014, Lesser prairie-chicken nest site selection, microclimate, and nest survival in association with vegetation response to a grassland restoration program: U.S. Geological Survey Open-File Report 2013-1235, 35 p., http://dx.doi.org/10.3133/ofr20131235.

ISSN 2331-1258 (online) 


\section{Acknowledgments}

Access to private property was provided by various landowners in Texas. We thank the Grasslans Charitable Foundation and Weaver Ranch in New Mexico for study site access and logistical and financial support. We thank A. Wood, P. Borsdorf, and a plethora of field technicians for their support in the field. We thank R. Cox, S. Cox, B. Dabbert, G. Perry, and M. Wallace for service on the graduate student committees and providing substantive review comments on the dissertation and thesis stemming from this research. Financial and logistical support for this project was provided by the Great Plains Landscape Conservation Cooperative, Texas Parks and Wildlife Department, New Mexico Game and Fish, Grasslans Charitable Foundation, U.S. Geological Survey Texas Cooperative Fish and Wildlife Research Unit, the Nature Conservancy, and Texas Tech Department of Natural Resources Management. This study was performed under the auspices of Texas Tech University animal care and use protocol no. 10052-08. 



\section{Contents}

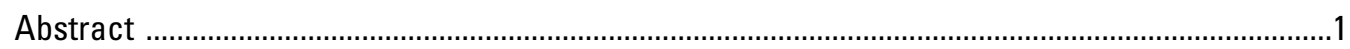

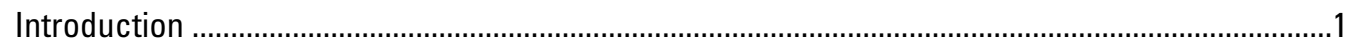

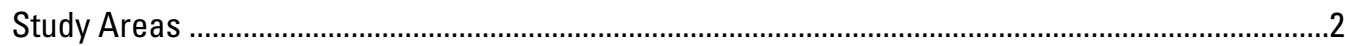

Herbicide and Grazing Treatments ............................................................................................

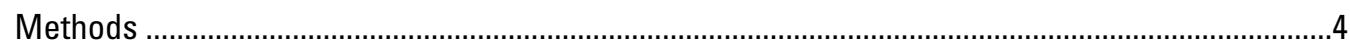

Literature Review ......................................................................................................................

In-Field Assessment of Thermal Ecology of Nesting Lesser Prairie-Chickens ........................4

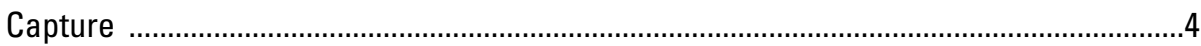

Microclimate Assessment .....................................................................................................

Microclimate Statistical Analysis .................................................................................

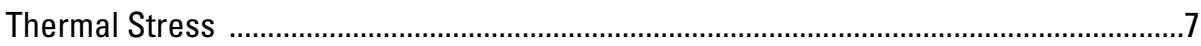

Thermal Stress Statistical Analysis .................................................................................7

Assessment of 10-Year Dataset ..........................................................................................7

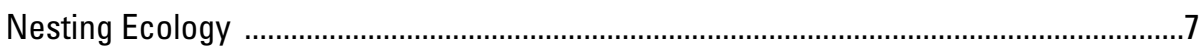

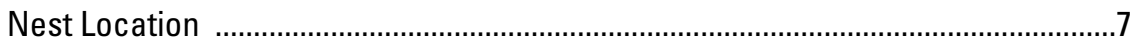

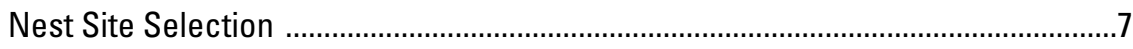

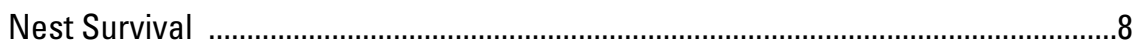

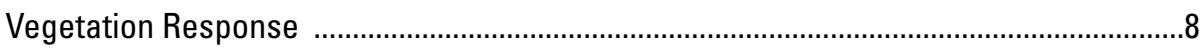

Precipitation, Soil Moisture, and Percent Composition ............................................

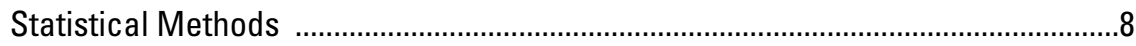

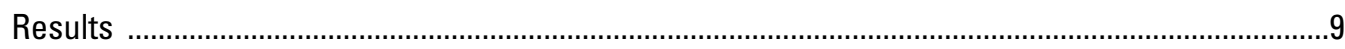

Literature Review ................................................................................................................9

In-Field Assessment of Thermal Ecology of Nesting Lesser Prairie-Chickens ......................10

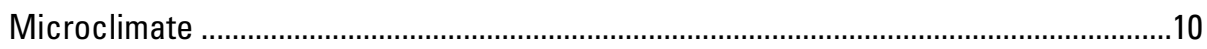

Thermal Stress ……………………………………………………………………...16

Assessment of 10-Year Dataset ...............................................................................................18

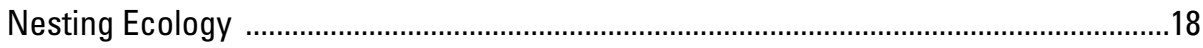

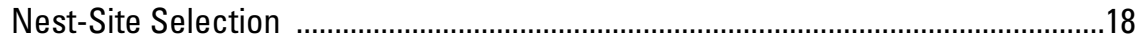

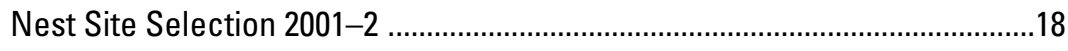

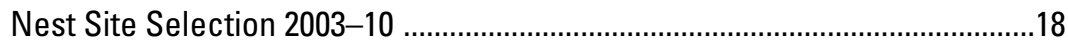

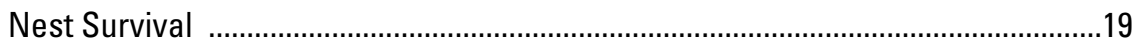

Vegetation Response …………………………………………………………………... 20

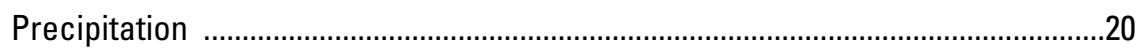

Soil Moisture …………………………………………………………………….....20

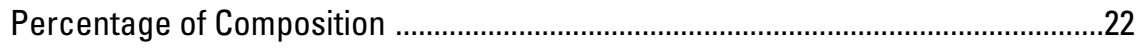

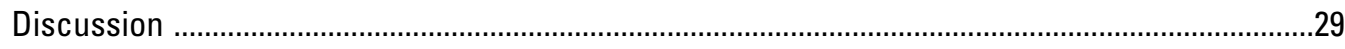

Microclimate and Thermal Stress .........................................................................................29

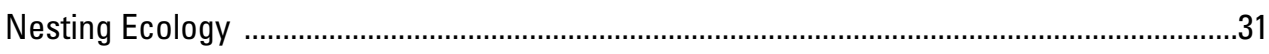

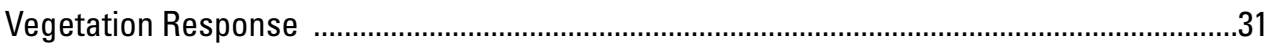

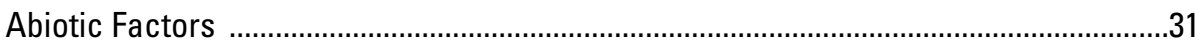

Rates of Tebuthiuron ....................................................................................................32

Changes in Composition .............................................................................................32

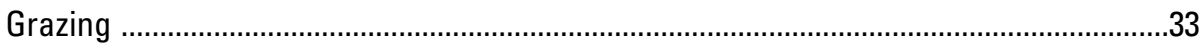

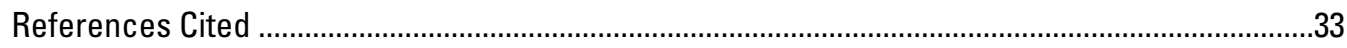




\section{Figures}

1. General outline of the New Mexico and Texas lesser prairie-chicken

(Tympanuchus pallidicinctus) research study areas, Roosevelt County, New

Mexico, and Cochran, Hockley, Terry, and Yoakum Counties, Texas, U.S.A., 2001-11

2. Study area in sand shinnery oak habitats of eastern New Mexico, showing application of tebuthiuron and grazing treatments that were applied in an assessment of restoration of habitats and lesser prairie-chicken response during 2001-11

3. Graph showing annual precipitation on study site in Roosevelt County, New Mexico, 2001-10

4. Graphs showing nest and outside temperatures, $A$, and relative humidity $(\mathrm{RH})$, $B$, for randomly selected bird (SPTX136) and date (May 6, 2010)

5. Graphs showing mean daylight nest, $A$, and outside temperatures, $B$, by date from 22 nests in Roosevelt County, New Mexico, and Cochran, Hockley, Terry, and Yoakum Counties, Texas, U.S.A., 2001-12

6. Graphs showing mean daylight nest, $A$, and outside relative humidity, $B$, by date from 22 lesser prairie-chicken nests in Roosevelt County, New Mexico, and Cochran, Hockley, Terry, and Yoakum Counties, Texas, U.S.A., 2001-12

7. Graphs showing mean daylight nest and outside temperature, $A$, and relative humidity, $B$, by week from 22 lesser prairie-chicken nests in Roosevelt County, New Mexico, and Cochran, Hockley, Terry, and Yoakum Counties, Texas, U.S.A., 2001-12

8. Graphs showing regression of environmental moisture and winter precipitation for April, $A$, and June, $B$, from a study of sand shinnery oak-grass communities in eastern New Mexico, 2002-10

9. Graphs showing soil moisture in April as a dependent variable in models testing the effect of herbicide, $A$, and grazing treatments, $B$, in sand shinnery oak grass communities in Roosevelt County, New Mexico, 2001-10

10. Graphs showing soil moisture in June as a dependent variable in models testing the effect of herbicide, $A$, and grazing treatments, $B$, in sand shinnery oak grass communities in Roosevelt County, New Mexico, 2001-10

11. Graphs showing percentage of composition of shrubs as a dependent variable in models testing the effect of herbicide, $A$, and grazing treatments, $B$, in sand shinnery oak grass communities in Roosevelt County, New Mexico, 2002-10

12. Graphs showing percentage of composition of grass as a dependent variable in models testing the effect of herbicide, $A$, and grazing treatments, $B$, in sand shinnery oak grass communities in Roosevelt County, New Mexico, 2002-10

13. Graphs showing percentage of composition of forbs as a dependent variable in models testing the effect of herbicide, $A$, and grazing treatments, $B$, in sand shinnery oak grass communities in Roosevelt County, New Mexico, 2002-10

14. Graphs showing percentage of composition of litter as a dependent variable in models testing the effect of herbicide, $A$, and grazing treatments, $B$, in sand shinnery oak grass communities in Roosevelt County, New Mexico, 2002-10

15. Graphs showing percentage of composition of bare ground as a dependent variable in models testing the effect of herbicide, $A$, and grazing treatments, $B$, in sand shinnery oak grass communities in Roosevelt County, New Mexico, 2002-10 
16. Graphs showing regression of sand shinnery oak, $A$, and sand bluestem, $B$, presence and winter precipitation from a study of sand shinnery oak grass communities in Roosevelt County, New Mexico, 2002-10

17. Graphs showing abundance of sand shinnery oak, in terms of percentage of composition, as a dependent variable in models testing the effect of herbicide, $A$, and grazing treatments, $B$, in sand shinnery oak grass communities in Roosevelt County, New Mexico, 2002-10

18. Graphs showing abundance of sand bluestem, in terms of percent composition, as a dependent variable in models testing the effect of herbicide, $A$, and grazing treatments, $B$, in sand shinnery oak grass communities in Roosevelt County, New Mexico, 2002-10

19. Graph showing nest and outside temperature and solar radiation for one nesting lesser prairie-chicken hen in 2012.

20. Graph showing nest and outside relative humidity and solar radiation for one nesting lesser prairie-chicken hen in 2012. Nest and outside relative humidity are the average value for each time interval for 10 days (May 15-25)

\section{Tables}

1. Vegetation composition and cover means from control and tebuthiuron-treated area vegetation transects in Roosevelt County, New Mexico, before and after 2000 tebuthiuron application

2. Description, names, and number of parameters for five a priori habitat treatment models used to assess daily nest survival rates for 197 lesser prairie-chicken nests in Roosevelt County, New Mexico, U.S.A., 2001-10

3. Study locations, years, sample sizes, initiation dates and clutch sizes for studies of record reporting phonological and reproductive data for lesser prairie-chickens

4. Temperature means, standard errors (SE), significance of differences $(p)$, and direction of nest temperature relative to external temperature at lesser prairiechicken nests in Roosevelt County, New Mexico, and Cochran, Hockley, Terry, and Yoakum Counties, Texas, U.S.A., 2001-12

5. Relative humidity means, standard errors (SE), significance of differences $(p)$, and direction of relative humidity relative to external conditions at lesser prairiechicken nests in Roosevelt County, New Mexico, and Cochran, Hockley, Terry, and Yoakum Counties, Texas, U.S.A., 2001-12

6. Detailed description of each complete flutter sequence from three nesting lesser prairie-chicken hens in Roosevelt County, New Mexico, and Cochran, Hockley, Terry, and Yoakum Counties, Texas, U.S.A., 2010, 2012

7. Changes in nest temperature and relative humidity while lesser prairie-chicken hen was off nest

8. Logistic regression model from 1,214 flutter observations of nesting lesser prairie-chicken hens from Roosevelt County, New Mexico, and Cochran, Hockley, Terry, and Yoakum Counties, Texas, U.S.A., 2010, 2012

9. Number of lesser prairie-chicken nests located in each treatment type for each year of study in Roosevelt County, New Mexico, 2001-10

10. Available nesting habitat, proportion of nests located in each treatment type, and the proportion of expected use for 100 randomly placed locations for five individual leks in Roosevelt County, New Mexico, 2003-10 
11. The proportion of nests observed for each treatment (TRT), 95 percent confidence interval for each observed proportion, the expected proportion for each treatment, and selection assessment for four leks in Roosevelt County, New Mexico, 2003-10

12. Output from five a priori models used to estimate daily nest survival rates for 181 lesser prairie-chicken nests in Roosevelt County, New Mexico, U.S.A., 2001-10 19

13. List of ranked Akaiki Information Criterion (AIC) models for precipitation, $\mathrm{AIC}_{\mathrm{c}^{\prime}}$ change in $\mathrm{AIC}_{c^{\prime}}$ and $\mathrm{AlC}_{\mathrm{c}}$ weights for soil moisture in April and June

14. List of top ranked Akaiki Information Criterion (AIC) models for precipitation, W, precipitation effect's $F$ and $P$ values, $r^{2}$, and trend of precipitation regression for soil moisture and plant composition

15. Summary of percent cover variables (grass, shrub, forb, litter, and bare ground) and their relationship with winter precipitation index, which was selected for the MANOVA following the trends of other plant variables

16. Overall MANCOVA results for percent cover and individual ANCOVA results for percentage of cover with associated $F$ and $P$ values

17. List of ranked Akaiki Information Criterion (AIC) models for precipitation, $\mathrm{AIC}_{\mathrm{c}^{\prime}}$ change in $\mathrm{AIC}_{\mathrm{c}^{\prime}}$ and $\mathrm{AIC}_{\mathrm{c}}$ weights for presence of sand shinnery oak and sand bluestem species

18. List of herbicide, grazing, and interaction effect for presence of sand shinnery oak and bluestem that were collected in 16 experimental plots consisting of the combinations of (1) tebuthiuron (herbicide) treated and grazed, (2) tebuthiuron treated and not grazed, (3) nontebuthiuron treated and grazed, and 


\section{Conversion Factors}

Inch/Pound to SI

\begin{tabular}{lcl}
\hline & Multiply & \multicolumn{1}{c}{ To obtain } \\
\hline inch (in.) & Length & \\
inch (in.) & 2.54 & centimeter $(\mathrm{cm})$ \\
foot (ft) & 25.4 & millimeter $(\mathrm{mm})$ \\
mile (mi) & 0.3048 & meter $(\mathrm{m})$ \\
mile, nautical $(\mathrm{nmi})$ & 1.609 & kilometer $(\mathrm{km})$ \\
yard $(\mathrm{yd})$ & 1.852 & kilometer $(\mathrm{km})$ \\
\hline & 0.9144 & meter $(\mathrm{m})$ \\
\hline acre & Area & \\
acre & 4,047 & square meter $\left(\mathrm{m}^{2}\right)$ \\
acre & 0.4047 & hectare $($ ha) \\
acre & 0.4047 & square hectometer $\left(\mathrm{hm}^{2}\right)$ \\
square foot $\left(\mathrm{ft}^{2}\right)$ & 0.004047 & square kilometer $\left(\mathrm{km}^{2}\right)$ \\
square foot $\left(\mathrm{ft}^{2}\right)$ & 929.0 & square centimeter $\left(\mathrm{cm}^{2}\right)$ \\
square inch $\left(\mathrm{in}^{2}\right)$ & 0.09290 & square meter $\left(\mathrm{m}^{2}\right)$ \\
section $\left(640 \mathrm{acres}^{2}\right.$ or $1 \mathrm{square}$ & 6.452 & square centimeter $\left(\mathrm{cm}^{2}\right)$ \\
mile $)$ & 259.0 & square hectometer $\left(\mathrm{hm}^{2}\right)$ \\
square mile $\left(\mathrm{mi}^{2}\right)$ & & \\
square mile $\left(\mathrm{mi}^{2}\right)$ & 259.0 & hectare $($ ha) \\
\hline & 2.590 & square kilometer $\left(\mathrm{km}^{2}\right)$ \\
\hline pounds per acre per year & & \\
\hline$(\mathrm{lb} / \mathrm{acre}) / \mathrm{yr}^{2}$ & & \\
\hline
\end{tabular}

Temperature in degrees Celsius $\left({ }^{\circ} \mathrm{C}\right)$ may be converted to degrees Fahrenheit $\left({ }^{\circ} \mathrm{F}\right)$ as follows:

${ }^{\circ} \mathrm{F}=\left(1.8 x^{\circ} \mathrm{C}\right)+32$

Temperature in degrees Fahrenheit $\left({ }^{\circ} \mathrm{F}\right)$ may be converted to degrees Celsius $\left({ }^{\circ} \mathrm{C}\right)$ as follows:

${ }^{\circ} \mathrm{C}=\left({ }^{\circ} \mathrm{F}-32\right) / 1.8$

Horizontal coordinate information is referenced to North American Datum of 1983 (NAD 83). 
SI to Inch/Pound

\begin{tabular}{|c|c|c|}
\hline Multiply & By & To obtain \\
\hline \multicolumn{3}{|c|}{ Length } \\
\hline centimeter $(\mathrm{cm})$ & 0.3937 & inch (in.) \\
\hline millimeter (mm) & 0.03937 & inch (in.) \\
\hline meter (m) & 3.281 & foot $(\mathrm{ft})$ \\
\hline kilometer (km) & 0.6214 & mile (mi) \\
\hline kilometer (km) & 0.5400 & mile, nautical (nmi) \\
\hline meter $(\mathrm{m})$ & 1.094 & yard (yd) \\
\hline \multicolumn{3}{|c|}{ Area } \\
\hline square meter $\left(\mathrm{m}^{2}\right)$ & 0.0002471 & acre \\
\hline hectare (ha) & 2.471 & acre \\
\hline square hectometer $\left(\mathrm{hm}^{2}\right)$ & 2.471 & acre \\
\hline square kilometer $\left(\mathrm{km}^{2}\right)$ & 247.1 & acre \\
\hline square centimeter $\left(\mathrm{cm}^{2}\right)$ & 0.001076 & square foot $\left(\mathrm{ft}^{2}\right)$ \\
\hline square meter $\left(\mathrm{m}^{2}\right)$ & 10.76 & square foot $\left(\mathrm{ft}^{2}\right)$ \\
\hline square centimeter $\left(\mathrm{cm}^{2}\right)$ & 0.1550 & square inch $\left(\mathrm{ft}^{2}\right)$ \\
\hline square hectometer $\left(\mathrm{hm}^{2}\right)$ & 0.003861 & $\begin{array}{l}\text { section (640 acres or } 1 \text { square } \\
\text { mile) }\end{array}$ \\
\hline hectare (ha) & 0.003861 & square mile $\left(\mathrm{mi}^{2}\right)$ \\
\hline square kilometer $\left(\mathrm{km}^{2}\right)$ & 0.3861 & square mile $\left(\mathrm{mi}^{2}\right)$ \\
\hline \multicolumn{3}{|c|}{ Application rate } \\
\hline $\begin{array}{l}\text { kilograms per hectare per year } \\
{[(\mathrm{kg} / \mathrm{ha}) / \mathrm{yr}]}\end{array}$ & 0.8921 & $\begin{array}{l}\text { pounds per acre per year } \\
{[(\mathrm{lb} / \mathrm{acre}) / \mathrm{yr}]}\end{array}$ \\
\hline
\end{tabular}

Temperature in degrees Celsius $\left({ }^{\circ} \mathrm{C}\right)$ may be converted to degrees Fahrenheit $\left({ }^{\circ} \mathrm{F}\right)$ as follows:

${ }^{\circ} \mathrm{F}=\left(1.8 x^{\circ} \mathrm{C}\right)+32$

Temperature in degrees Fahrenheit $\left({ }^{\circ} \mathrm{F}\right)$ may be converted to degrees Celsius $\left({ }^{\circ} \mathrm{C}\right)$ as follows:

${ }^{\circ} \mathrm{C}=\left({ }^{\circ} \mathrm{F}-32\right) / 1.8$

Horizontal coordinate information is referenced to North American Datum of 1983 (NAD 83). 


\title{
Lesser Prairie-Chicken Nest Site Selection, Microclimate, and Nest Survival in Association with Vegetation Responses to a Grassland Restoration Program
}

\author{
By Clint W. Boal, ${ }^{1}$ Blake A. Grisham, ${ }^{2}$ David A. Haukos, ${ }^{3}$ Jennifer C. Zavaleta, ${ }^{2}$ and Charles Dixon ${ }^{4}$
}

\section{Abstract}

Climate models predict that the region of the Great Plains Landscape Conservation Cooperative (GPLCC) will experience increased maximum and minimum temperatures, reduced frequency but greater intensity of precipitation events, and earlier springs. These climate changes along with different landscape management techniques may influence the persistence of the lesser prairie-chicken (Tympanuchus pallidicinctus), a candidate for protection under the Endangered Species Act and a priority species under the GPLCC, in positive or negative ways. The objectives of this study were to conduct (1) a literature review of lesser prairiechicken nesting phenology and ecology, (2) an analysis of thermal aspects of lesser prairie-chicken nest microclimate data, and (3) an analysis of nest site selection, nest survival, and vegetation response to 10 years of tebuthiuron and/or grazing treatments.

We found few reports in the literature containing useful data on the nesting phenology of lesser prairie-chickens; therefore, managers must rely on short-term observations and measurements of parameters that provide some predictive insight into climate impacts on nesting ecology. Our field studies showed that prairie-chickens on nests were able to maintain relatively consistent average nest temperature of $31{ }^{\circ} \mathrm{C}$ and nest humidities of 56.8 percent whereas average external temperatures $\left(20.3-35.0^{\circ} \mathrm{C}\right)$ and humidities $(35.2-$ 74.9 percent) varied widely throughout the 24 hour (hr) cycle. Grazing and herbicide treatments within our experimental areas were designed to be less intensive than in common practice. We determined nest locations by radio-tagging hen lesser prairie-chickens captured at leks, which are display grounds at which male lesser prairie-chickens aggregate and

\footnotetext{
${ }^{1}$ U.S. Geological Survey Texas Cooperative Fish and Wildlife Research Unit, Texas Tech University, Lubbock, TX 79409.

2 Department of Natural Resources Management, Texas Tech University, Lubbock, TX 79409.

${ }^{3}$ U.S. Geological Survey Kansas Cooperative Fish and Wildlife Research Unit, Kansas State University, Manhattan, KS 66506.

${ }^{4}$ Wildlife Plus Consulting, Alto, NM 88312.
}

attempt to attract a female for mating. Because nest locations selected by hen lesser prairie-chicken are strongly associated with the lek at which they were captured, we assessed nesting habitat use on the basis of hens captured at individual leks, and then for all leks pooled. There was no clear pattern of selection for treatment type for nest placement among hens associated with individual leks; however, when hens from all leks were pooled, we found nesting lesser prairie-chickens selected control plots for nesting over plots that were grazed, treated with tebuthiuron, or were both grazed and treated with tebuthiuron. Overall, the probability of a nest surviving the incubation period was 0.57 for this study and did not vary significantly among treatment types. In contrast to nesting preference for untreated habitats, lek use exhibited no noticeable selection of treatment type.

Over the 10 years of the habitat management study, there was 91 percent less sand shinnery oak (Quercus havardii) in treated areas than untreated areas. The removal of sand shinnery oak made environmental soil moisture more available for grasses and forbs to germinate and grow. Grasses increased by 149 percent and forbs increased by 257 percent in treated areas as compared to untreated areas throughout the study period. Our combined results, including our habitat selection analysis at the individual lek level, indicated that reduced rates of herbicide and short-duration grazing treatments were not detrimental to nesting lesser prairie-chickens and that populations of lesser prairie-chickens in shrub-dominated ecosystems may benefit from reduced rates of herbicide application and short duration of grazing that results in increased habitat heterogeneity.

\section{Introduction}

The lesser prairie-chicken (Tympanuchus pallidicinctus) has experienced as much as a 97 percent decline in population size (USFWS, 2011) and similar suspected reduction in occupied areas from historic levels. The species is currently undergoing review for listing as a threatened or endangered species under the United States Endangered Species Act. The lesser prairie-chicken is a priority species under the Great 
Plains Landscape Conservation Cooperative (GPLCC) and State wildlife conservation plans. The semiarid region of the Southern Great Plains encompasses the entire distribution of the lesser prairie-chicken, which is considered to be the principal indicator species of the ecosystem (Giesen, 1998). We are involved in studies of lesser prairie-chicken nesting and brood-rearing ecology (Grisham, 2012), overwinter and breeding survival (Boal and Pirius, 2012), and habitat use in west Texas and eastern New Mexico (Boal and others, unpub. data, 2012). Similar studies have been, and are being, conducted elsewhere across the distribution of the prairie-chicken including Kansas, Colorado, and Oklahoma; however, the influence of drought and climate change on lesser prairie-chickens has, to date, been largely overlooked (Grisham, 2012). This lack of information is of concern because prairie-chickens are sensitive to landscape alterations and drought (Hamerstrom and Hamerstrom, 1961; Crawford, 1980). Drought is suspected to negatively influence lesser prairie-chickens through reduced growth of vegetation that provides nesting, roosting, and escape cover and food (Merchant, 1982; Grisham, 2012). Furthermore, there is evidence that home range sizes increase during drought years (Merchant, 1982), and recruitment is lower after drought years (Merchant, 1982; Giesen, 1998). Landscape alterations and management (for example, herbicide treatment of shrubs and grazing systems) appear to influence resource selection, survival, and reproductive success of lesser prairie-chicken populations (Haukos and Smith, 1989; Olawsky and Smith, 1991; Johnson and others, 2004); however, specific (that is, long-term) population parameters and vital rates necessary for development of models of response to predicted climate change are lacking. Furthermore, despite substantial efforts to conserve lesser prairie-chickens and their habitats, the thermal ecology of the species is unknown and virtually no information is available for predictive modeling of the role climate change may have on the nesting ecology of this species.

One of the primary science goals for the Landscape Conservation Cooperatives and the U.S. Geological Survey National Climate Change and Wildlife Science Center is to assess the vulnerability and risk of species to climate change. Furthermore, the issue of climate change as a challenge to bird conservation in arid and semiarid regions was identified by Federal and State fish and wildlife management agencies as a high priority issue (http://nccwsc.usgs.gov/). A key issue in conservation of lesser prairie-chickens in context of climate change is that the thermal ecology of the species, many specific vital rates, and long-term responses to habitat alterations are unknown. As such, virtually no information is available allowing predictive modeling of the role climate change may have on the reproductive ecology of the species, which is important in that the GPLCC region is anticipated to experience increased maximum and minimum temperatures, increased intensity of reduced frequency but greater intensity of precipitation events, and spring and the associated environmental phenology occurring earlier. In particular, climate change forecasts indicate that the southern Great Plains will become drier with more frequent extreme heat events and decreased precipitation events (Karl and others, 2009); thus, lesser prairie-chickens may be exposed to increased temperatures and decreased humidity that may exceed not only their own tolerance levels but that of their eggs. Increased surface and ambient temperatures and reduced humidity may lead to egg death and (or) nest abandonment. These impacts may be exacerbated if, because of low precipitation, nesting phenology shifts to later in the year when temperatures are increased and humidity decreased (Grisham, 2012).

There are multiple goals for our studies in west Texas and eastern New Mexico. First was our objective of conducting a literature review for existing information on lesser prairiechicken nesting phenology and nesting ecology. Second was an in-field assessment of the thermal ecology of lesser prairie-chickens derived by collection of new data on thermal and humidity profiles at active nests and thermally associated behaviors of nesting lesser prairie-chickens. Our final goal was to analyze and assess a 10 -year dataset of lesser prairiechicken response to herbicide and grazing treatments. This assessment included documentation of vegetation response to treatments and lesser prairie-chicken nest site selection and nest survival in response to the treatments. Admittedly, we recognize that this regional, time-limited project will not answer all the questions regarding climate change, reproductive ecology, and nesting resource selection of lesser prairie-chickens; however, we believe it will provide a compilation and analysis of existing phenological data, new nest climate data, and an assessment of archived data that will be a valuable contribution toward development of predictive models of response to future climate change. Our results provide an important tool for long-term conservation of this imperiled species by allowing simulations of spatial and temporal risk assessment for adaptive management options by conservation agencies. This is the final project report that includes results for the objectives: (1) a literature review of lesser prairie-chicken nesting phenology and ecology, (2) an analysis of thermal aspects of lesser prairie-chicken nest microclimate data, and (3) the analysis of the 10-year dataset in terms of nest site selection, nest survival, and vegetation response to herbicide and grazing treatments.

\section{Study Areas}

The study area included privately owned lands in Cochran, Hockley, Terry, and Yoakum counties in Texas and privately and publicly owned lands in Roosevelt County, New Mexico (fig. 1). The soils in the area include Brownfield and Tivoli series; characterized by deep, loose, light-colored, neutral sandy soils and deep, loose, light-colored sands that occur as 2 to 5 meter $(\mathrm{m})$ high dunes with slopes as great as 30 percent (Newman, 1964). The landscape was composed of a matrix of grassland, cropland, and gently undulating 


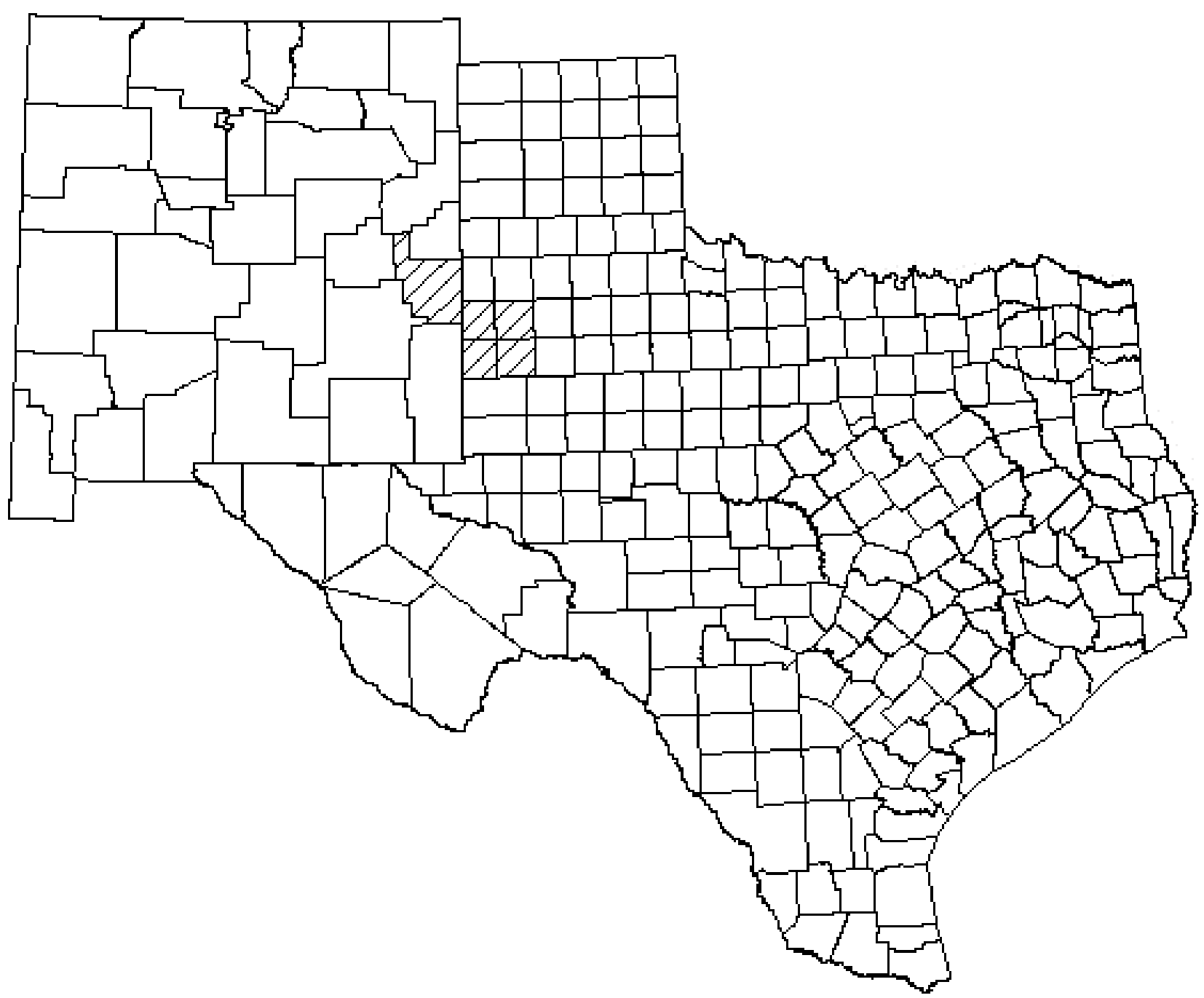

Figure 1. General outline of the New Mexico and Texas lesser prairie-chicken (Tympanuchus pallidicinctus) research study areas, Roosevelt County, New Mexico, and Cochran, Hockley, Terry, and Yoakum Counties, Texas, U.S.A., 2001-11. Hatched boxes represent study area county boundaries.

sandhills and was dominated by sand shinnery oak (Quercus havardii) and sand sagebrush (Artemisia filifolia) shrubs with mixed grasses and forbs. Common grasses include little bluestem (Schizachyrium scoparium), sand dropseed (Sporobolus cryptandrus), purple three-awn (Aristida purpurea), and sand paspalum (Paspalum setaceum) (Pettit, 1979; Woodward and others, 2001). Common forbs include silverleaf nightshade (Solanum elaeagnifolium), spectacled pod (Dimorphocarpa wislizeni), Indian blanket (Gaillardia pulchella), woolly locoweed (Astragalus mollissimus), common sunflower (Helianthus annuus), scarlet gaura (Oenothera suffrutescens), and halfshrub sundrop (Oenothera serrulata). In other areas, mesquite (Prosopis glandulosa) was invasive and encroaching upon native rangeland (Hagen and others, 2004). Strahan (2008) provided a complete floristic survey of the plants located in the sand shinnery oak communities of eastern New Mexico. Average annual precipitation in the area is 45.9 centimeters $(\mathrm{cm})$, with most precipitation falling from May to October (Newman, 1964). Temperatures range from 44 to $-33^{\circ} \mathrm{C}$; July is the hottest month with a mean temperature of $25^{\circ} \mathrm{C}$, and January is the coldest month with a mean temperature of $2.4^{\circ} \mathrm{C}$ (Newman, 1964). The major land uses for this study were cattle production, row-crop agriculture, and oil and natural 
gas extraction. Common surrounding row crops were cotton and grain sorghum (Crawford and Bolen, 1975). Although the study sites are separated by a political boundary, there are no genetic or other biological differences between lesser prairie-chicken populations that occur in these counties (Corman, 2011).

\section{Herbicide and Grazing Treatments}

The New Mexico study area was partitioned into 16 plots of about 65 hectares (ha) (one plot was 80 ha), each assigned one of four combinations of herbicide and grazing treatments: treated not grazed (T-NG), treated and grazed (T-G), not treated and grazed (NT-G), and a control of not treated and not grazed (NT-NG) (fig. 2). The pellet form of the herbicide tebuthiuron was applied from an airplane at 0.60 $\mathrm{kg} / \mathrm{ha}$ to 532 ha of private land in 2000. The adjacent North Bluitt Prairie Chicken Area was not treated with herbicide. The rate of herbicide application was less than 50 percent of the recommended rates (1 kilogram per hectare [ $\mathrm{kg} / \mathrm{ha}]$ ) to ensure that sand shinnery oak was not eliminated from the community (Peterson and Boyd, 1998; Haukos, 2011). The North Bluitt Prairie Chicken Area was not grazed 7 years prior to treatment. The private lands were not grazed 2 years prior to herbicide treatment, and neither were grazed during the first 2 years after the herbicide treatment. The grazing treatment was a short-duration system in which plots were grazed once during the dormant season (January and February) and once during the growing season (July). The stocking rate was calculated each season on the basis of measured forage production and designed to remove 25 percent of available herbaceous material per season. A prevegetation survey conducted in 2000 found that the vegetation community in the study area was homogenous prior to application of the herbicide and grazing treatments (table 1).

\section{Methods}

\section{Literature Review}

To examine historical patterns of lesser prairie-chicken nesting phenology, clutch sizes, and nesting success, we did an intensive literature search to locate and review all published and unpublished reports and sought out voluntary contributions from collaborators of unpublished data.

\section{In-Field Assessment of Thermal Ecology of Nesting Lesser Prairie-Chickens}

\section{Capture}

Subadult and adult lesser prairie-chickens were captured on leks with walk-in funnel traps, rocket nets, and drop-nets during spring (March-April) from 2001-12. Upon capture of the lesser prairie-chickens, we recorded sex, age, lek of capture, time of capture, weight, wing cord, pinnae length, and tail length. Sex was determined by pinnae length, presence of eye comb, tail feather markings, and other plumage characteristics (Copelin, 1963). Age was determined by wing feather plumage characteristics (Copelin, 1963). We banded each captured individual with a New Mexico Game and Fish or Texas Parks and Wildlife Department aluminum blunt-end leg band and equipped with a 13-gram, loop style radio-transmitter (Advanced Telemetry Systems, Ashanti, Minnesota, U.S.A.; Telemetry Solutions, California, U.S.A.; or Wildlife Materials, Murphysboro, Illinois, U.S.A.) equipped with an 8-hour mortality censor, then released at the capture site.

\section{Microclimate Assessment}

We relocated radio-tagged hens daily by triangulation. We approached the hen via homing to determine nest locations when locations remained unchanged for 3 days or more (Pitman and others, 2006). We counted the number of eggs in each nest (clutch size) and then marked nest locations with a hand-held Garmin Etrex Vista Global Positioning System unit.

We placed one Maxim Integrated Semiconductor data logger (Maxim Integrated Products, Sunnyville, Calif., U.S.A.; hereafter "ibutton") inside the nest bowl and one outside of the nest bowl to record ambient air temperature and relative humidity (hereafter $\mathrm{RH}$ ) at 10-minute ( $\mathrm{min}$ ) intervals (categories hereafter are nest temperature, nest RH, outside temperature, outside RH). All temperatures were ${ }^{\circ} \mathrm{C}$, and $\mathrm{RH}$ was defined as the ratio of water vapor mass per kilogram of dry air in a parcel of air (www.mesonet.ttu.edu; Accessed August 17, 2010). We placed the outside ibutton in the same vegetative substrate that constituted the nest bowl. For example, if the nest bowl was found in sand bluestem (Andropogon gerardii ssp. hallii), we put the outside ibutton on the perimeter of the nest bowl in the same plant. We collected the ibuttons within 3 days of nest failure or success. 


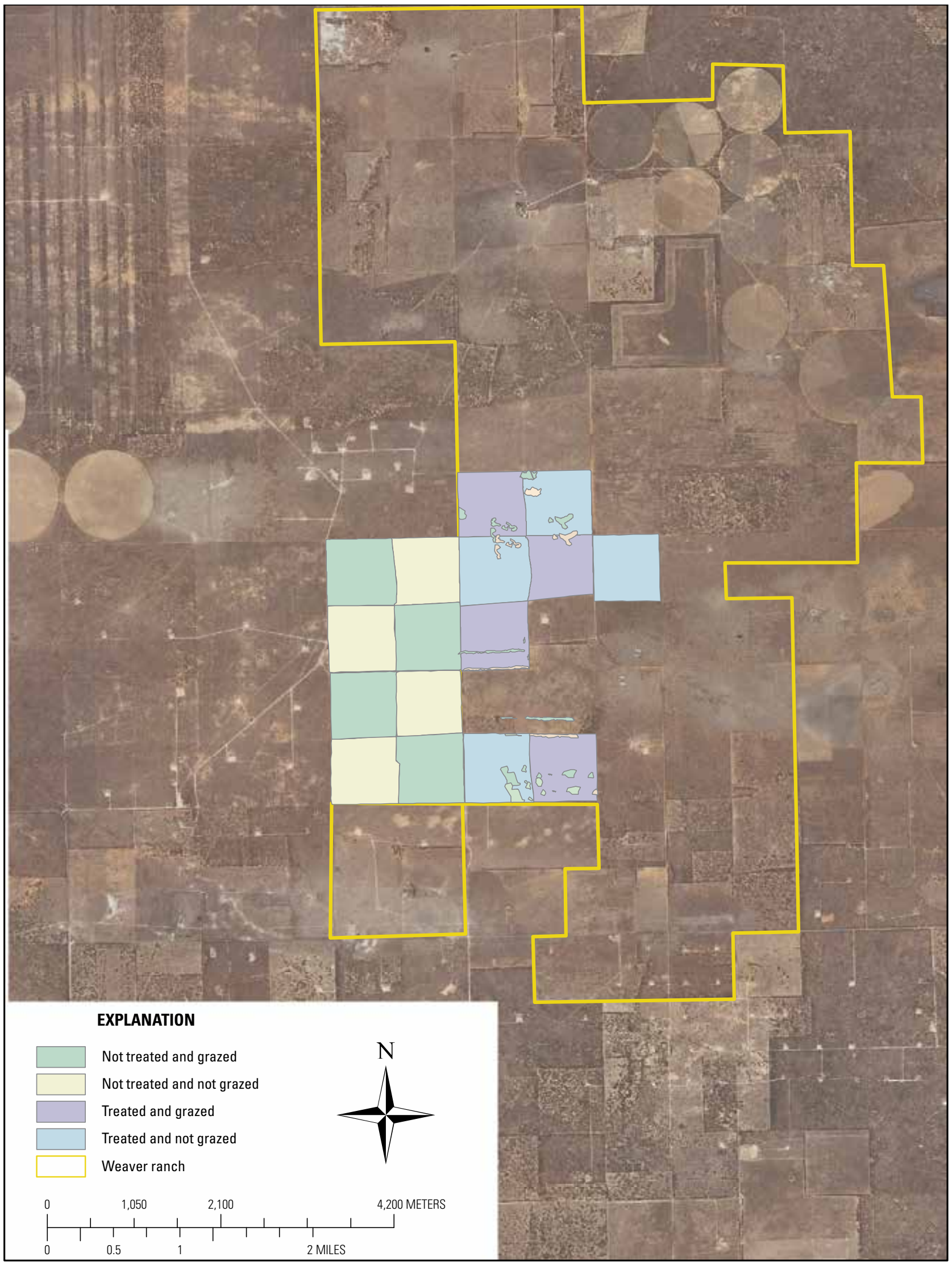

Figure 2. Study area in sand shinnery oak habitats of eastern New Mexico, showing application of tebuthiuron and grazing treatments that were applied in an assessment of restoration of habitats and lesser prairie-chicken response during 2001-11. 
Table 1. Vegetation composition and cover means from control and tebuthiuron-treated area vegetation transects in Roosevelt County, New Mexico, before and after 2000 tebuthiuron application. Preapplication data were collected in 2000; postapplication data were collected in 2001.

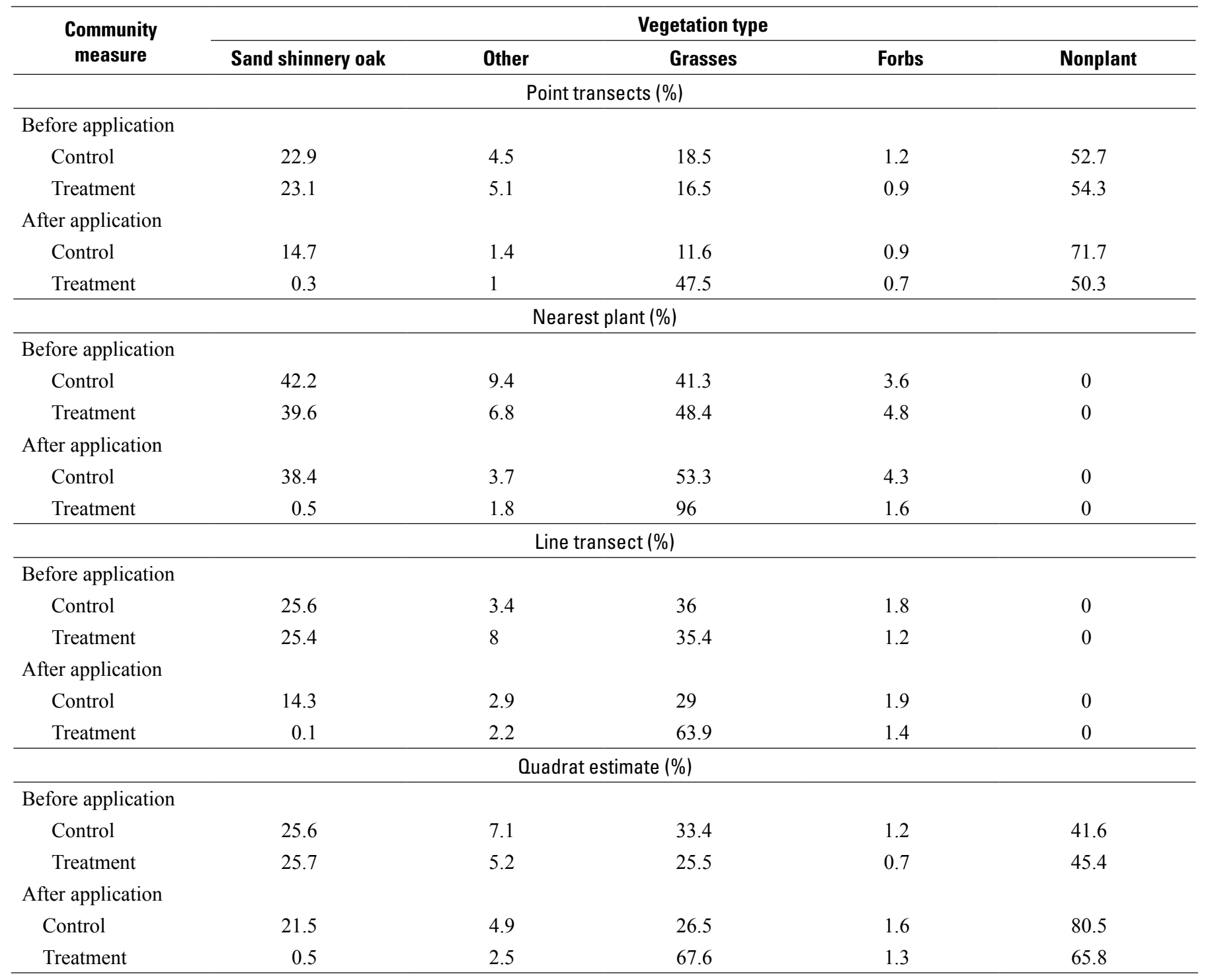

\section{Microclimate Statistical Analysis}

We sorted ibutton data by day and corresponding bird. We then calculated mean (and associated standard errors), maximum, and minimum values of nest temperature, nest $\mathrm{RH}$, outside temperature, and outside $\mathrm{RH}$ for each nest and each day in Proc MEANS in SAS version 9.2 (SAS Institute, Cary, North Carolina, U.S.A.). We calculated the mean nest temperature and mean outside temperature for the morning (6 a.m.-9 a.m.), midmorning (9:01 a.m.-12 p.m.), midday (12:01 p.m.-3 p.m.), afternoon (3:01 p.m.-6 p.m.), evening (6:01 p.m.-9 p.m.) and nighttime (9:01 p.m.-5:59 a.m.) hours. We compared these values by using a factorial analysis of variance (hereafter ANOVA) in PROC GLM in SAS version 9.2. We used temperature as the response variable and time period (morning, midmorning, midday, afternoon, evening, night) and location (nest/outside) as the factorial explanatory variables. We calculated the least square means for each combination by using lsmeans in PROC GLM in SAS version 9.2. We also assessed if nest and outside temperatures and RHs differed throughout the duration of the nesting season on a weekly basis by using a factorial ANOVA. We defined week 1 as May 4-13, week 2 as May 14-20, week 3 as May 21-27, week 4 as May 28-June 3, week 5 as June 4-10, week 6 as June 11-17, week 7 as June 18-21, and week 8 as June 22-28. We used temperature as the response variable and week, location, and time period as the factorial explanatory variables. We calculated the least square means for each combination by using lsmeans in PROC GLM in SAS version 9.2 . 


\section{Thermal Stress}

We used video surveillance of lesser prairie-chicken nests to assess if a hen was exhibiting signs of thermal stress via gular fluttering. We placed one GardenWatchCam (Brinno Inc., Palm City, Florida, U.S.A.; hereafter "nest-camera") at 13 nests. We set each nest-camera $1 \mathrm{~m}$ from the nest bowl and approximately $0.5 \mathrm{~m}$ above the ground. We camouflaged the nest-camera with camouflage duct-tape and surrounding vegetation. We programmed each camera to record one photograph every five seconds in 2010 and every $10 \mathrm{~min}$ in 2011-12; we modified the image capture rate in 2011-12 to allow for longer periods of data collection without nest visit and possible disturbance and to be consistent with the time interval at which thermal and humidity data were being collected. We collected camera data within 3 days of nest failure or success.

\section{Thermal Stress Statistical Analysis}

We reviewed video data from each camera to monitor when hens engaged in gular fluttering. We describe gular fluttering as follows: neck and head stretched out perpendicular to body (opposed to head and neck tucked into body) with bill gaping and "in and out" motions of the throat (Dawson, 1982). At each 10-min interval, we recorded gular flutter $(0=$ no, $1=$ yes $)$ and the corresponding nest temperature, nest RH, outside temperature, and outside RH from the ibutton data. We used 10-min intervals because the ibutton data collection schedule restricted our observations to 10-min samples. For each hen, we assessed the number of flutter sequences (defined as when the hen starts gular fluttering and continues until stopping) per day, the duration of each sequence, nest and outside temperatures when the flutter sequence begins and ends, and time spent off nest. We modeled the probability of a hen going into gular flutter based on outside nest temperature and outside relative humidity by using PROC LOGISTIC in SAS version 9.2. We used flutter as the binary response variable and outside nest temperature and relative humidity as the explanatory variables.

\section{Assessment of 10-Year Dataset}

\section{Nesting Ecology}

\section{Nest Location}

Nest locations of radio-tagged hens were determined by approaching the hen via homing when locations remained unchanged for two subsequent location attempts. Hens were not flushed off the nest in this study, but if they did inadvertently flush off the nest, observers counted the number of eggs present. When hens were located, the nest coordinates were recorded with a Global Positioning System unit. Each observer then moved $2 \mathrm{~m}$ north of the nest site, and a picture of the nest site was sketched for future records. A photograph of each nest was taken from the 2-m interval and the hen's frequency, band number, and age were recorded. In some cases a radio transmitter was placed $2 \mathrm{~m}$ north of the nest site to monitor the location of the hen in relation to the nest site. Habitat treatment combination/type was recorded for each nest site.

\section{Nest Site Selection}

We imported the Universal Transverse Mercator (UTM) coordinate of each nest into ArcGIS 9.2 to verify treatment assignment recorded on each datasheet. For nests that did not fall within a specific treatment plot, we used digital orthophoto quarter quads (DOQQs) from 2005 to reflect vegetative cover on the study area. We did not use 2009 DOQQs because an adjacent ranch was treated with tebuthiuron in 2009 and subsequently created a confounding factor within the original study design. All nests located on this ranch in 2009-10 were removed from treatment selection analysis. We incorporated the dune systems on the study area as polygon themes in ArcGIS 9.2. Additionally, we used hill shade layers in ArcGIS 9.2 to verify the digitized sand dunes to accurately assign treatment type when a nest fell within a dune system. We used grazing records from landowners to assign "grazing" or "no grazing" to nests that fell outside of a specific treatment plot.

We assessed nest site selection at the lek-specific level (Grisham, 2012). We assessed nest site selection within individual leks of capture by using a type III design described by Manly and others (2002), wherein we identified individuals and assessed available resource units. For this analysis, the individual units were nests from lesser prairie-chickens that were captured at the same lek, and the available resource units are defined as the available treatment types within the buffer placed around the lek of capture. To assess the available nesting habitat, we used ArcGIS 9.2 to develop a polygon that incorporated a $1.9-\mathrm{km}$ buffer around each lek of capture on the study area. The mean distance from an individual's nest to the lek of capture was $1.7 \mathrm{~km}(n=155 ; \mathrm{SE}=12.3)$ (Grisham, 2012; Davis, 2009) in this study. We used a 1.9-km buffer around each lek because $1.9 \mathrm{~km}$ was the upper bound of the 95 percent confidence limit for distance to lek of capture. We used a one way chi-squared test by using PROC FREQ in SAS version 9.2 to assess if lesser prairie-chickens were selecting treatments for nesting by comparing differences in the number of nests located in each treatment type (used) versus the total proportion of 100 randomly placed locations that is expected to occur within each treatment in the available nesting habitat. We calculated the 95 percent confidence interval for the percentage of nests observed in each treatment type for each test using the following equation: $\hat{p} \pm Z_{a / 2} \sqrt{p q / n}$ (Zar, 2010). We considered that a treatment was used more or less than expected if the chi-square test was significant and the expected proportion of nests in an individual treatment fell outside of the observed 95 percent confidence interval. 
For our analysis, we assessed 2001-2 separate from other years because the amount of treatment types available differed because there was no grazing on the herbicide-treated areas during these years. Additionally, we only used the leks of capture in 2001-2 to assess available nesting habitat for this segment of the analysis.

\section{Nest Survival}

We used the logit-link function within the nest survival model in program MARK to assess daily nest survival from 2001-10. We developed five a priori models (Smythe and Haukos, 2009) to assess the effects of treatment combination on daily nest survival rates (table 2). We used Akaike's Information Criterion for small samples ( $\mathrm{AIC}_{\mathrm{c}}$ ), changes in $\mathrm{AIC}_{\mathrm{c}}$ and change in $\mathrm{AIC}_{\mathrm{c}}$ values, and Akaike weights $\left(\mathrm{AIC}_{\mathrm{w}}\right.$ ) to evaluate model performance and select the best approximating model (Anderson and others, 2000).

\section{Vegetation Response}

\section{Precipitation, Soil Moisture, and Percent Composition}

We measured precipitation, soil moisture, and percent composition in each treatment plot from 2001-10. A digital recording rain gage (Rainwise Inc., Harbor, Maine, U.S.A.) was established in the New Mexico study area to monitor precipitation. In addition, a weather station was placed near the site to monitor daily weather conditions, including monthly precipitation. Because precipitation in semiarid regions is defined as being low and highly variable (Noy-Meir, 1973; Sala and Lauenroth, 1982), potential precipitation variables for each year within the vegetation response assessment were calculated as winter I (November to March), winter II (October to March), growing season (April to October), and annual season (April to March).

We measured soil moisture in April and June in each plot from 2001-10 with a quick-draw soil moisture meter (Aquaterr model 200, Aquaterr Instruments and Automation, Costa Mesa, Calif., U.S.A.) with the exception of April 2002,
June 2002, and June 2008. We measured soil moisture by placing the probe 15 centimeters $(\mathrm{cm})$ into the soil at $10-\mathrm{m}$ intervals along three $100-\mathrm{m}$ line transects in a randomly selected direction from a permanently marked location in each plot. Soil moisture was recorded in centibars (cb).

We conducted vegetative surveys each September from 2001-10 to monitor vegetation response to treatments. Within each replicate, we measured percent composition of grass, shrub, forb, bare ground, and litter every meter along 3, 10 $m$ transects (Heady and others, 1959). Percent composition of grass, shrub, forb, bare ground, and litter within each replication was estimated by dividing the number of points at which each occurred by the total number of points sampled. Also, we assessed percent composition of sand shinnery oak and sand bluestem within each plot as measures of shrub eradication and forage plant production, respectively.

\section{Statistical Methods}

Soil moisture exerts a relative influence on each measured, dependent variable included in this study. Thus, determination of a relevant precipitation index for each dependent variable was necessary to create a covariate that removed the maximum amount of variation caused by annual precipitation. These indices enabled us to test the relative effects of the treatments while minimizing the effect of annual precipitation, which varied from $21-82 \mathrm{~cm}$ during the study (fig. 3).

For each dependent variable, we tested four indices of precipitation that were biologically relevant for deep sand ecosystems, using April 1 and October 1 as the start and end of the growing season, respectively. These four indices are previous annual precipitation (April 1 to March 31), spring/ summer precipitation (April 1 to September 30), and two measures of winter precipitation (October 1 to March 31 and November 1 to March 31). Historically (1981-2010), average precipitation from April to March was $42.45 \mathrm{~cm}$, from April to October was $36.3 \mathrm{~cm}$, from October to March was $9.77 \mathrm{~cm}$, and from November to March was $6.16 \mathrm{~cm}$ (WRCC, 2010). We chose two different indices of winter precipitation because temporal variation in winter precipitation has been used as

Table 2. Description, names, and number of parameters for five a priori habitat treatment models used to assess daily nest survival rates for 197 lesser prairie-chicken nests in Roosevelt County, New Mexico, U.S.A., 2001-10.

[NT-G, not treated and grazed; NT-NG, not treated and not grazed; T-G, treated and grazed; T-NG, treated and not grazed]

\begin{tabular}{lll}
\hline \multicolumn{1}{c}{ Model } & \multicolumn{1}{c}{ Name } & \multicolumn{1}{c}{ Description } \\
\hline $\mathrm{S}_{\text {Same }}$ & All treatments same & No difference in survival across treatments. \\
$\mathrm{S}_{\text {NT-G=T-G;NT-NG=T-NG}}$ & Grazing & No difference in survival across similar grazing treatments. \\
$\mathrm{S}_{\text {Different }}$ & All treatments different & Survival differs across all treatments. \\
$\mathrm{S}_{\mathrm{NT}-\mathrm{G}=\mathrm{T}-\mathrm{NG} ; \mathrm{NT}-\mathrm{NG}=\mathrm{T}-\mathrm{G}}$ & Reciprocal & No difference in survival between treatments that have different herbicide and \\
& & grazing applications. \\
$\mathrm{S}_{\mathrm{NT}-\mathrm{G}=\mathrm{NT}=\mathrm{NG} ; \mathrm{T}-\mathrm{G}=\mathrm{T}=\mathrm{NG}}$ & Herbicide & No difference in survival across similar herbicide treatments. \\
\hline
\end{tabular}




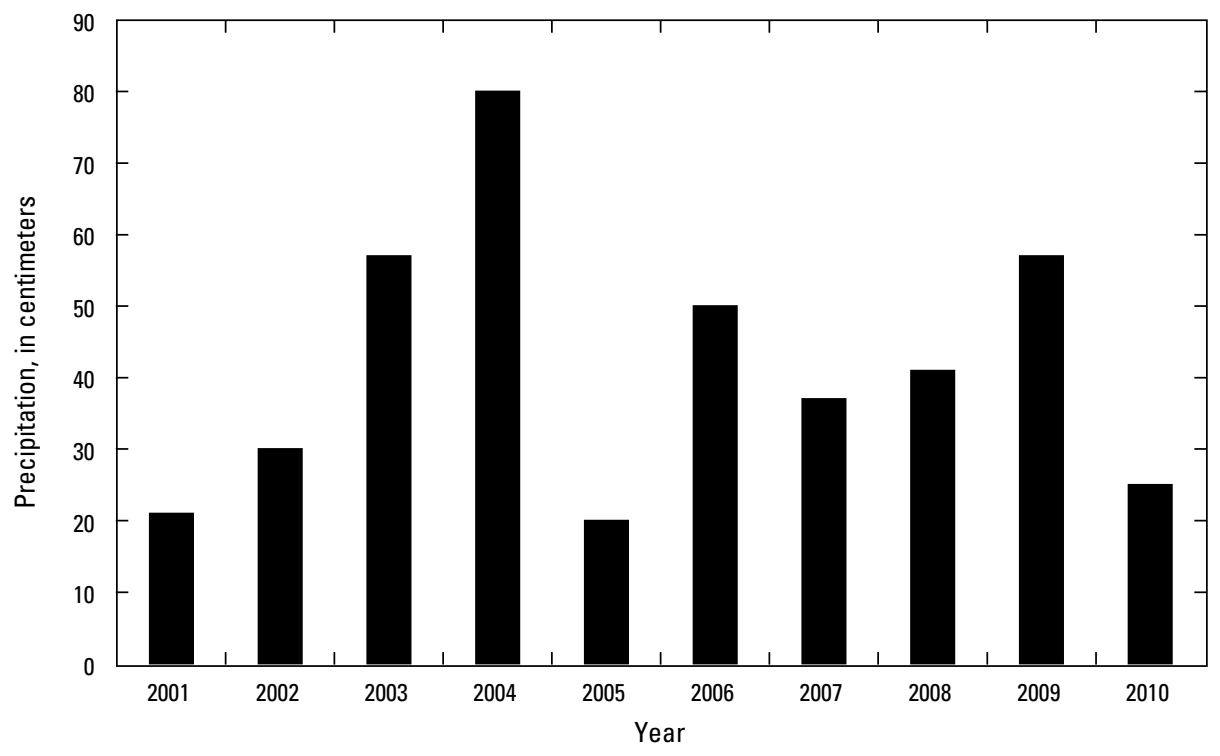

Figure 3. Annual precipitation on study site in Roosevelt County, New Mexico, 2001-10. The 10 year precipitation average for the study area was 41 centimeters.

a predictor variable for topographic features in the region (Brown and Comrie, 2002). We assessed growing-season precipitation because plant structure may be related to growth during the previous growing season. We also tested annual precipitation, which is a combination of spring and winter precipitation.

Precipitation was treated as a continuous, fixed effect each year. For each dependent variable, we used AICc to rank models containing four precipitation indices to assess which index had the greatest influence on each dependent variable within our model set (Anderson and others, 2000). The resultant precipitation measure from the highest ranking model was used as a covariate in a multivariate analysis of covariance (MANCOVA), removing the effect of variation in annual precipitation prior to testing the main effects of herbicide treatment (treated vs. untreated) and grazing (grazing vs. non-grazed) as well as their interaction. Plant species composition was categorized into groups of vegetation types (grass, shrub, and forb) as well as variables for bare ground and litter. If the MANCOVA results were statistically significant, we used a univariate mixed effects analysis of variance (ANCOVA) to test each dependent variable in the same study design. We used Satterthwaite's approximation to pool variances among the independent variables of herbicide treatment, grazing, and herbicide* grazing if residuals were homogenous (Zar, 2010). If the precipitation covariate was significant $(P<0.05)$, we used simple linear regression to evaluate the strength of the influence of the precipitation measure on the dependent variable. We performed statistical analyses by using PROC MIXED in SAS 9.2. Data were tested for normality and homogeneity of variance (Cochran and Cox, 1957). Because our samples were randomly selected, we assumed independence. We set $\alpha=0.05$ for all statistical tests.

\section{Results}

\section{Literature Review}

We conducted an extensive review and search for information on clutch initiation dates and brood sizes for lesser prairie-chickens because there is a dearth of information available on these subjects. We found 3 studies from Texas, 2 from New Mexico, 2 from Oklahoma, and 1 from Kansas from which we could find data on some or all of the parameters of nest initiation dates and clutch sizes (table 3 ). These reports averaged 3.6 years of data. Mean nest initiation ranged from as early as April 25 in 2005 in New Mexico (Davis, 2009) to as late as May 28 in Oklahoma (Copelin, 1963); however, Copelin's (1963) data must be interpreted cautiously because it consists of a small sample of 10 nests from across a wide time range (1920-59). In general, mean initiation dates appear to be in early to mid-May (table 3), but all these studies pooled both initial and renesting dates except Pitman and others (2006), Davis (2009), and our study. We found no correlation between date and clutch size for 7 datasets from 6 studies $(r=0.28, P=0.54)$. 
Table 3. Study locations, years, sample sizes, initiation dates and clutch sizes for studies of record reporting phonological and reproductive data for lesser prairie-chickens.

[*, Parameter estimates for juvenile birds are in parentheses; ${ }^{\wedge}$, no mean was indicated by authors]

\begin{tabular}{|c|c|c|c|c|c|c|}
\hline Location & Year(s) & $n$ & $\begin{array}{c}\text { Mean } \\
\text { initiation date }\end{array}$ & $\begin{array}{c}\text { Mean } \\
\text { Julian date }\end{array}$ & $\begin{array}{c}\text { Mean } \\
\text { clutch size }\end{array}$ & Study \\
\hline Texas & $2008-11$ & 33 & May 15 & 135 & 7.48 & Grisham, 2012 \\
\hline Texas & $1987-88$ & 13 & May 13 & 133 & 7.83 & Haukos, 1988 \\
\hline Oklahoma & 1920, 1956, 1959 & 10 & May 28 & 148 & 11.2 & Copelin, 1963 \\
\hline Kansas & & $15(13)^{*}$ & June 1 & $152.9(153.9)$ & $7.3(8.2)$ & \\
\hline \multirow[t]{2}{*}{ New Mexico } & 2004 & 7 & May 7 & 127 & Range 6-12 & Davis, 2009 \\
\hline & 2005 & 14 & April 25 & 115 & Range 6-12 & \\
\hline Oklahoma & 1999-2003 & $N / A$ & $N / A$ & $N / A$ & 10.85 & Wolf and others, 2003 \\
\hline
\end{tabular}

${ }^{1}$ Clutch size was not determined for every nest.

\section{In-Field Assessment of Thermal Ecology of Nesting Lesser Prairie-Chickens}

\section{Microclimate}

We collected 29,650 recordings of nest temperature, nest $\mathrm{RH}$, outside temperature, and outside RH from 22 LEPC nests (10 from Texas, 12 from New Mexico) in 2010-12. Outside temperatures and RH fluctuated widely with time of day whereas nest temperatures and $\mathrm{RH}$ were relatively constant within nests in context to outside conditions, suggesting regulation by the nesting hen (fig. $4 A, 4 B$; tables 4 , $5)$. In general, nests were warmer than external temperatures throughout the 24-hr period except for the afternoon and midday, and midmorning, during which nests were cooler (table 4). Nests averaged $31.0^{\circ} \mathrm{C}$ with an average range of 28.5-33.48 ${ }^{\circ} \mathrm{C}$, whereas external temperatures averaged 26.0 ${ }^{\circ} \mathrm{C}$ with an average range from $20.3-35.1^{\circ} \mathrm{C}$. Mean relative humidity was similarly consistent among nests $(\bar{x}=56.8$, range 50.1-62.1) compared to external measures $(\bar{x}=55.28$, range 34.6-74.8). Relative humidity at nests was greater than external throughout the 24-hr period except during nighttime and early morning hours (table 5). 

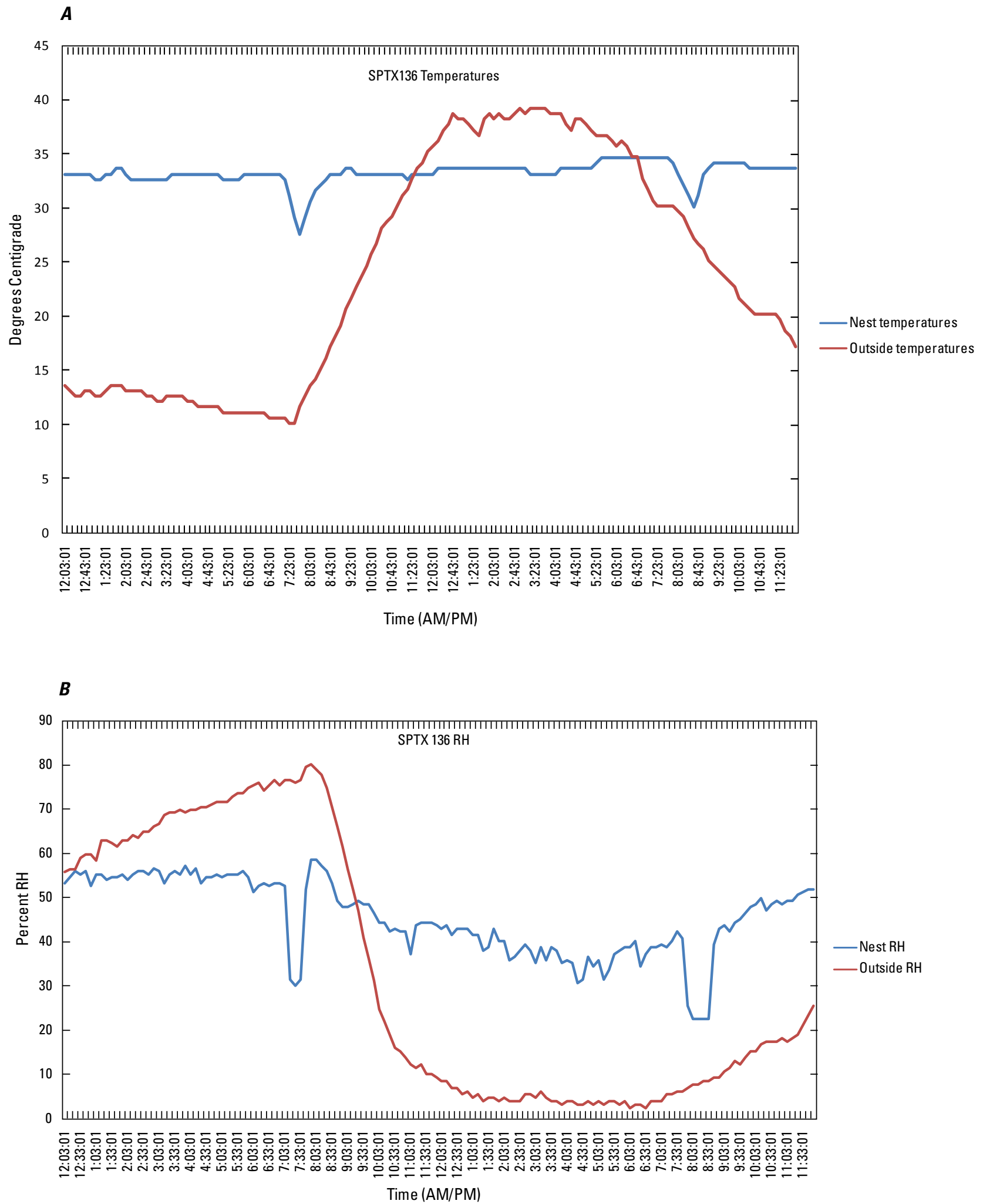

Figure 4. Nest and outside temperatures, $A$, and relative humidity (RH), $B$, for randomly selected bird (SPTX136) and date (May 6, 2010). 
Table 4. Temperature means, standard errors (SE), significance of differences $(p)$, and direction of nest temperature relative to external temperature at lesser prairie-chicken nests in Roosevelt County, New Mexico, and Cochran, Hockley, Terry, and Yoakum Counties, Texas, U.S.A., 2001-12.

\begin{tabular}{lllllllll}
\hline \multirow{2}{*}{ Time } & \multicolumn{2}{c}{ Nest } & & \multicolumn{2}{c}{ External } & \multirow{2}{*}{$\boldsymbol{p}$} & $\begin{array}{c}\text { Nest } \\
\text { temp }\end{array}$ \\
\cline { 2 - 3 } & Mean & SE & & Mean & SE & & & \\
\hline Morning & 28.56 & 0.1 & & 20.38 & 0.1 & $<0.0001$ & $\uparrow$ \\
Midmorning & 31.06 & 0.1 & & 38.68 & 0.1 & $<0.0001$ & $\downarrow$ \\
Afternoon & 33.38 & 0.1 & & 34.06 & 0.1 & 0.0002 & $\downarrow$ \\
Midday & 33.48 & 0.1 & & 35.11 & 0.1 & $<0.0001$ & $\downarrow$ \\
Evening & 30.88 & 0.1 & & 27.03 & 0.1 & $<0.0001$ & $\uparrow$ \\
Night & 30.07 & 0.1 & & 20.89 & 0.06 & $<0.0001$ & $\uparrow$ \\
\hline
\end{tabular}

We compiled daily average recordings of nest temperature, nest $\mathrm{RH}$, outside temperature, and outside $\mathrm{RH}$ for the daylight hours. Mean nest temperature $(\bar{x}=30.96$, $\mathrm{SE}=0.02)$ was significantly warmer than outside temperature $\left(\bar{x}=26.06, \mathrm{SE}=0.05 ; t_{59302}=77.65, P<0.001\right)$ and mean nest RH $(\bar{x}=56.80, \mathrm{SE}=0.09)$ was statistically more humid than outside $\mathrm{RH}\left(\bar{x}=55.28, \mathrm{SE}=0.16 ; t_{59302}=8.08\right.$, $P<0.001)$ during the daylight hours, but varied little biologically. Nest temperatures were different from outside nest temperatures as the nesting season progressed
Table 5. Relative humidity means, standard errors (SE), significance of differences $(p)$, and direction of relative humidity relative to external conditions at lesser prairie-chicken nests in Roosevelt County, New Mexico, and Cochran, Hockley, Terry, and Yoakum Counties, Texas, U.S.A., 2001-12.

\begin{tabular}{lcccccccc}
\hline \multirow{2}{*}{ Time } & \multicolumn{2}{c}{ Nest } & & \multicolumn{2}{c}{ External } & & Nest \\
\cline { 2 - 3 } & Mean & SE & & Mean & SE & & & RH \\
\hline Morning & 62.18 & 0.33 & & 74.87 & 0.33 & $<0.0001$ & $\downarrow$ \\
Midmorning & 57.91 & 0.33 & & 53.48 & 0.33 & $<0.0001$ & $\uparrow$ \\
Afternoon & 50.05 & 0.33 & & 34.69 & 0.33 & $<0.0001$ & $\uparrow$ \\
Midday & 51.98 & 0.33 & & 37.19 & 0.33 & $<0.0001$ & $\uparrow$ \\
Evening & 52.06 & 0.33 & & 44.44 & 0.33 & $<0.0001$ & $\uparrow$ \\
Night & 60.17 & 0.19 & 66.37 & 0.19 & $<0.0001$ & $\downarrow$ \\
\hline
\end{tabular}

$\left(F_{13,59290}=1011.10, P<0.001\right.$; fig. $\left.5 A, 5 B\right)$. Additionally, nest RH were different from outside $\mathrm{RH}$ as the nesting season progressed $\left(F_{13,59290}=1012.32, P<0.001\right.$; fig. $\left.6 A, 6 B\right)$. Mean nest temperature remained consistent throughout the nesting season whereas mean outside temperatures increased throughout the nesting season (fig. 7A). With the exception of week 1 , mean nest humidity remained constant throughout the nesting season, whereas mean outside relative humidity fluctuated throughout the nesting season with no noticeable temporal pattern (fig. 7B). 

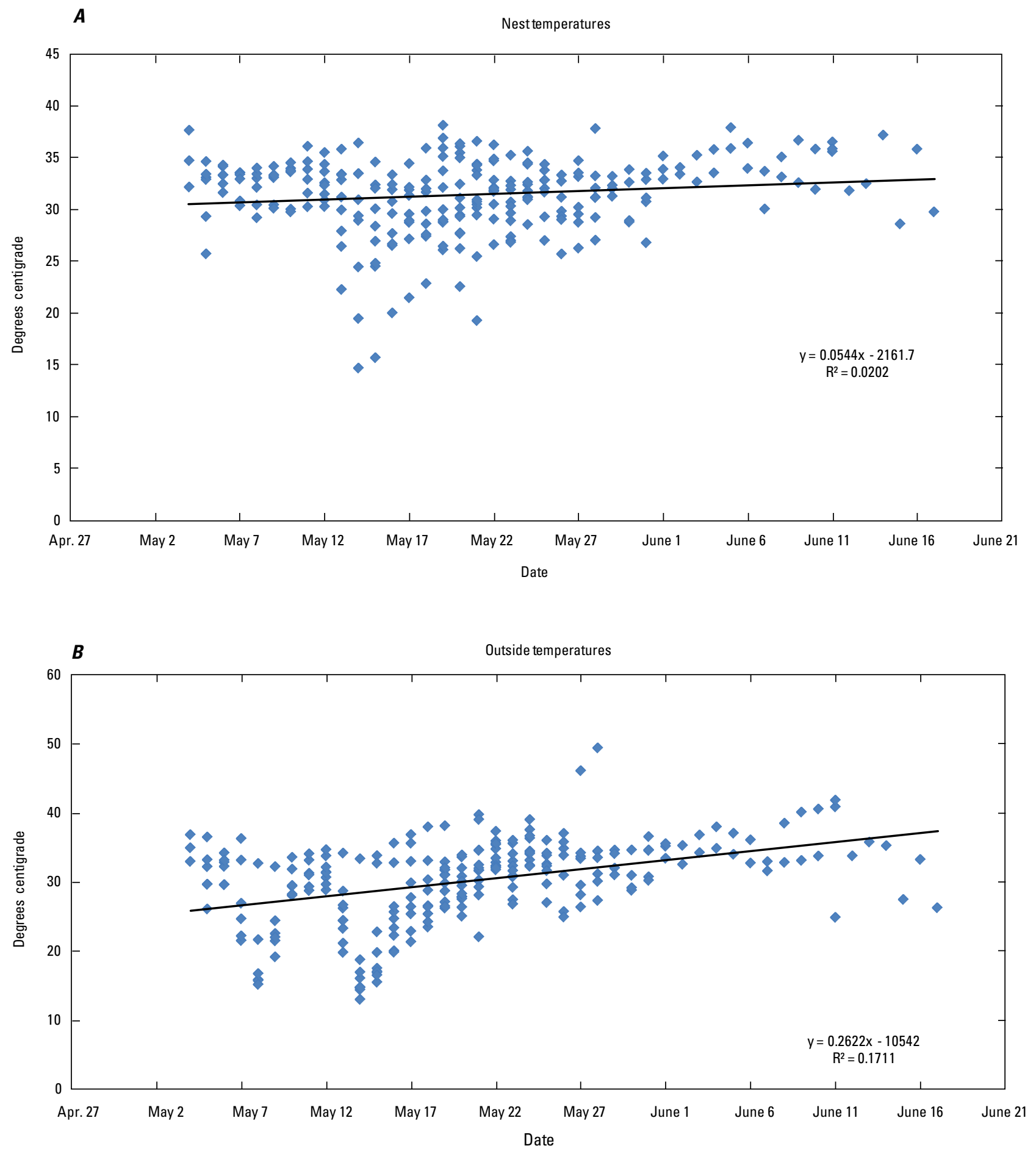

Figure 5. Mean daylight nest, $A$, and outside temperatures, $B$, by date from 22 nests in Roosevelt County, New Mexico, and Cochran, Hockley, Terry, and Yoakum Counties, Texas, U.S.A., 2001-12. Each data point represents the mean daylight temperature (nest or outside) for one nest for the represented day. 

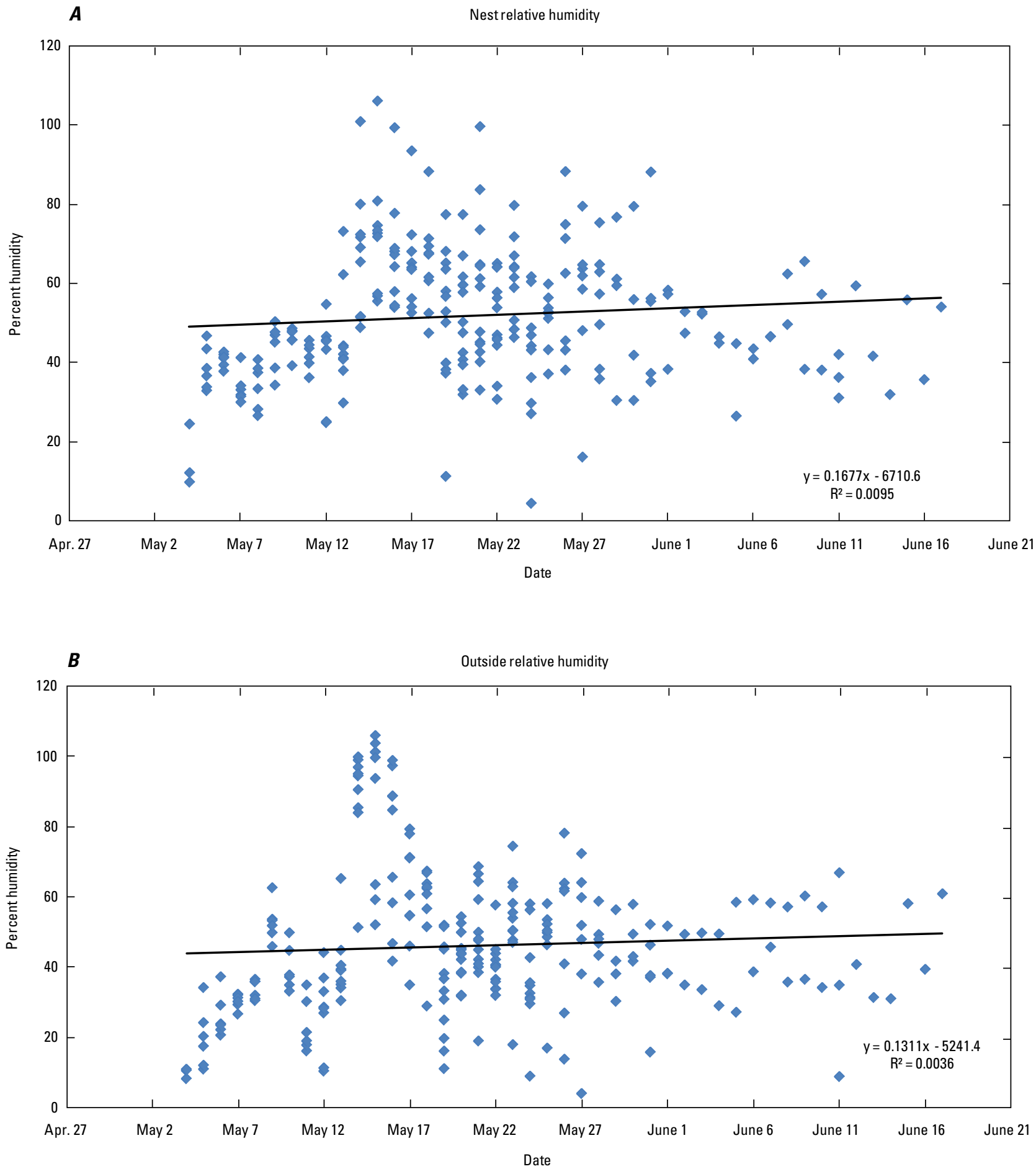

Figure 6. Mean daylight nest, $A$, and outside relative humidity, $B$, by date from 22 lesser prairie-chicken nests in Roosevelt County, New Mexico, and Cochran, Hockley, Terry, and Yoakum Counties, Texas, U.S.A., 2001-12. Each data point represents the mean daylight temperature (nest or outside) for one nest for the represented day. 

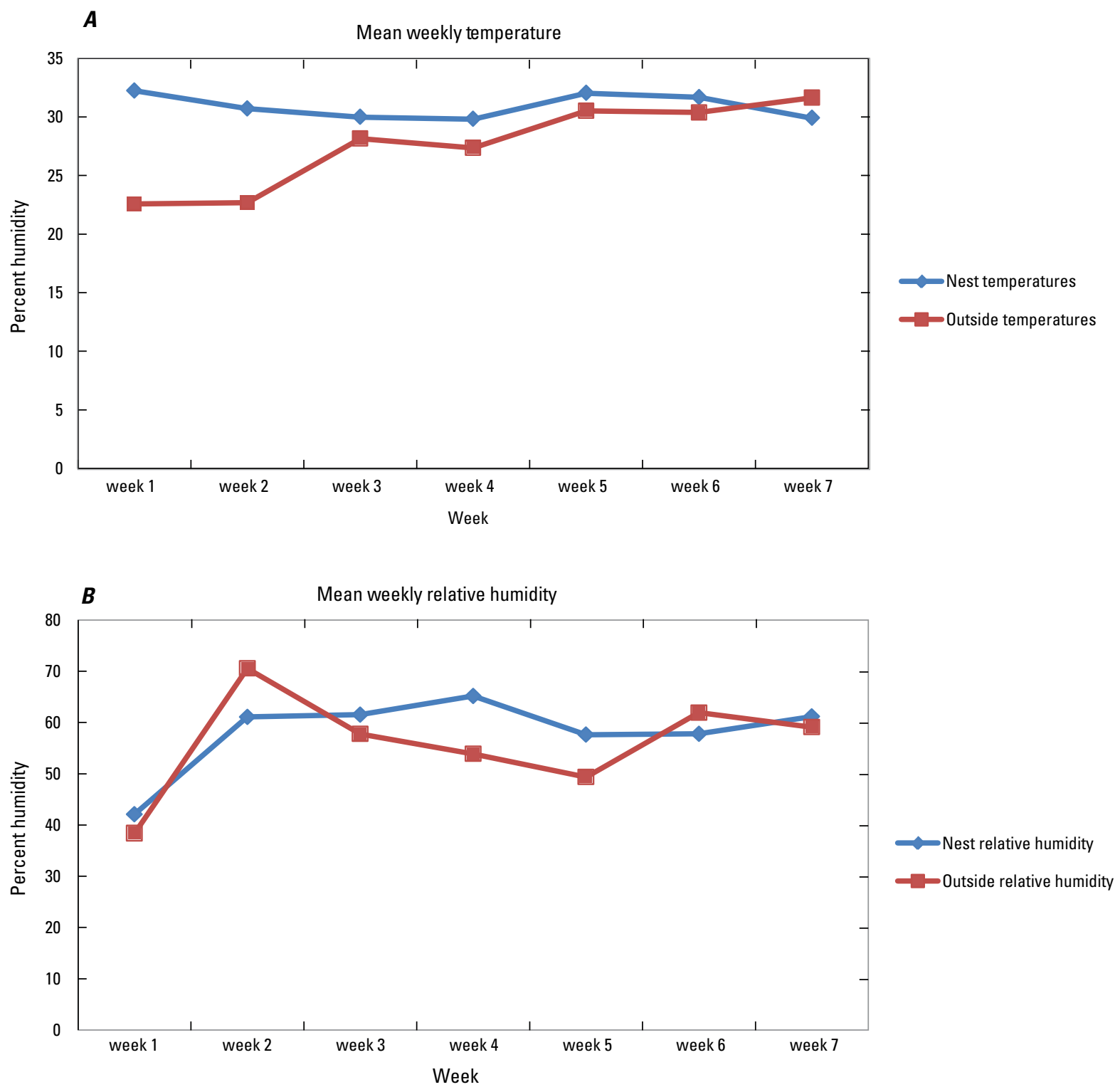

Figure 7. Mean daylight nest and outside temperature, $A$, and relative humidity, $B$, by week from 22 lesser prairie-chicken nests in Roosevelt County, New Mexico, and Cochran, Hockley, Terry, and Yoakum Counties, Texas, U.S.A., 2001-12. Each data point represents the mean daylight temperature or humidity (nest or outside) for all nests combined for the represented week. 


\section{Thermal Stress}

During the 2010 season, we were able to place nestcameras at 5 nests. We were unable to place cameras at nests in 2011 because of the lack of nesting attempts by lesser prairie-chickens in the study area; only 3 of 15 hens attempted to incubate and all failed within 3 days of initiation of incubation. In 2012, we placed cameras at 8 nests, but we were only able to use footage from 1 nest because of 6 nest failures. In total, we obtained usable footage from 5 nests; 1 nest-camera was inadvertently blocked by vegetation. We also had to eliminate data for 2 hens ( 1 in 2010, 1 in 2012) because of faulty ibutton readings. Ultimately, we obtained 15 complete flutter sequences from 3 birds. Each flutter sequence typically lasted for more than 5 hours, and once a hen began to flutter she did so continuously without breaks until stopping (table 6). Hens left the nest twice a day, once in the morning (5 a.m. -8 a.m.) and once in the evening (6 p.m. $-8: 30$ p.m.). Duration of off-nest events varied but tended to last less than 1 hour (table 7). When the hen was off nest, temperatures and relative humidity tended to decrease (fig. $4 A, 4 B$; table 7).

We recorded 284 flutter observations from 3 nesting hens in 2010 and 930 flutter observations from 1 nesting hen in 2012. Ambient air temperature and relative humidity were good predictors of gular flutter $\left(r^{2}=0.41\right.$; table 8$)$. The relationship between ambient air temperature and relative humidity and gular flutter was:

$$
\begin{aligned}
\text { flutter }= & \mathrm{e} 0.1614(\text { airtemp })-0.02 \text { (humidity)-3.44/1 } \\
& -\mathrm{e} 0.1614(\text { airtemp) }-0.02 \text { (humidity)-3.44 }
\end{aligned}
$$

Table 6. Detailed description of each complete flutter sequence from three nesting lesser prairie-chicken hens in Roosevelt County,

\begin{tabular}{|c|c|c|c|c|c|c|c|c|c|c|c|c|}
\hline Bird ID & Day & $\begin{array}{l}\text { Start } \\
\text { time }\end{array}$ & $\begin{array}{l}\text { End } \\
\text { time }\end{array}$ & $\begin{array}{c}\text { Dura- } \\
\text { tion }\end{array}$ & $\begin{array}{c}\text { Nest } \\
\text { tempera- } \\
\text { ture at } \\
\text { start }\end{array}$ & $\begin{array}{c}\text { Nest } \\
\text { tempera- } \\
\text { ture at } \\
\text { finish }\end{array}$ & $\begin{array}{c}\text { Outside } \\
\text { tempera- } \\
\text { ture at } \\
\text { start }\end{array}$ & $\begin{array}{c}\text { Outside } \\
\text { tempera- } \\
\text { ture at } \\
\text { finish }\end{array}$ & $\begin{array}{c}\text { Nest } \\
\text { relative } \\
\text { humidity } \\
\text { at start }\end{array}$ & $\begin{array}{c}\text { Nest } \\
\text { relative } \\
\text { humidity } \\
\text { at finish }\end{array}$ & $\begin{array}{c}\text { Outside } \\
\text { relative } \\
\text { humidity } \\
\text { at start }\end{array}$ & $\begin{array}{c}\text { Outside } \\
\text { relative } \\
\text { humidity } \\
\text { at finish }\end{array}$ \\
\hline HEN127 & June 19, 2010 & $10: 52$ & $15: 52$ & $5: 00$ & 32.65 & 34.65 & 31.74 & 35.73 & 65.58 & 57.02 & 67.62 & 57.08 \\
\hline SPTX134 & May 19,2010 & $10: 35$ & $16: 45$ & $6: 10$ & 26.08 & 38.57 & 28.18 & 47.61 & 39.11 & 36.26 & 63.49 & 5.86 \\
\hline \multirow{8}{*}{ SPTX229 } & May 15,2012 & $11: 44$ & $19: 04$ & $8: 20$ & 23.15 & 28.15 & 29.72 & 22.22 & 77.15 & 55.87 & 69.53 & 38.46 \\
\hline & May 16,2012 & $12: 00$ & $19: 00$ & 7:00 & 25.65 & 28.65 & 33.21 & 27.72 & 68.41 & 72.27 & 27.32 & 26.57 \\
\hline & May 17, 2012 & $11: 00$ & $19: 00$ & $8: 00$ & 26.15 & 29.15 & 27.22 & 29.22 & 64.48 & 62.78 & 35.53 & 21.99 \\
\hline & May 18,2012 & $11: 00$ & 20:00 & 9:00 & 26.15 & 30.15 & 30.22 & 30.22 & 68.41 & 46.39 & 34.05 & 11.87 \\
\hline & May 22, 2012 & $11: 30$ & 20:00 & $8: 30$ & 28.15 & 30.65 & 28.72 & 31.21 & 62.21 & 48.19 & 47.79 & 21.99 \\
\hline & May 23, 2012 & $9: 30$ & 20:00 & $10: 30$ & 28.65 & 31.65 & 30.71 & 33.94 & 52.35 & 25.19 & 31.82 & 3.08 \\
\hline & May 24, 2012 & $10: 00$ & $21: 00$ & 11:00 & 29.65 & 31.15 & 35.71 & 29.22 & 39.07 & 21.95 & 18.91 & 7.90 \\
\hline & May 25, 2012 & $10: 00$ & $20: 30$ & $10: 30$ & 30.15 & 30.65 & 32.21 & 31.21 & 49.39 & 20.00 & 22.76 & 12.60 \\
\hline
\end{tabular}
New Mexico, and Cochran, Hockley, Terry, and Yoakum Counties, Texas, U.S.A., 2010, 2012. 
Table 7. Changes in nest temperature and relative humidity while lesser prairie-chicken hen was off nest.

\begin{tabular}{|c|c|c|c|c|c|c|c|c|c|}
\hline $\begin{array}{c}\text { Bird } \\
\text { identification }\end{array}$ & Date & $\begin{array}{l}\text { AM/ } \\
\text { PM }\end{array}$ & $\begin{array}{c}\text { Duration } \\
\text { off nest }\end{array}$ & $\begin{array}{l}\text { Beginning } \\
\text { temperature }\end{array}$ & $\begin{array}{c}\text { End } \\
\text { temperature }\end{array}$ & $\begin{array}{c}\text { Change } \\
\text { in nest } \\
\text { temperature }\end{array}$ & $\begin{array}{l}\text { Beginning } \\
\text { humidity }\end{array}$ & $\begin{array}{c}\text { End } \\
\text { humidity }\end{array}$ & $\begin{array}{c}\text { Change } \\
\text { in nest } \\
\text { humidity }\end{array}$ \\
\hline \multirow{2}{*}{ SPTX134 } & May 19, 2010 & PM & $1: 20$ & 39.06 & 34.08 & -4.98 & 36.65 & 32.67 & -3.98 \\
\hline & May 20, 2010 & PM & $0: 50$ & 35.58 & 29.59 & -5.99 & 35.55 & 39.11 & 3.56 \\
\hline \multirow[t]{3}{*}{ Hen127NM } & June 18,2010 & $\mathrm{AM}$ & $0: 50$ & 21.74 & 22.24 & 0.5 & 80.3 & 85.42 & 5.12 \\
\hline & June 18,2010 & $\mathrm{PM}$ & $0: 50$ & 34.23 & 29.47 & -4.76 & 50.14 & 46.97 & 3.17 \\
\hline & June 19,2010 & PM & $1: 32$ & 35.23 & 34.23 & -1 & 52.03 & 59.49 & 7.46 \\
\hline \multirow[t]{19}{*}{ SPTX229 } & May 15, 2012 & $\mathrm{AM}$ & $0: 20$ & 22.65 & 22.65 & 0 & 79.28 & 79.28 & 0 \\
\hline & May 15, 2012 & $\mathrm{PM}$ & 1:00 & 26.65 & 23.65 & -3 & 48.19 & 57.62 & 9.43 \\
\hline & May 16, 2012 & $\mathrm{AM}$ & $0: 40$ & 24.65 & 21.15 & -3.5 & 67.85 & 58.2 & -9.65 \\
\hline & May 16, 2012 & $\mathrm{PM}$ & $0: 30$ & 28.65 & 26.15 & -2.5 & 66.17 & 59.93 & 6.24 \\
\hline & May 17, 2012 & $\mathrm{AM}$ & $0: 40$ & 25.65 & 23.65 & -2 & 68.88 & 60.24 & -8.64 \\
\hline & May 17, 2012 & $\mathrm{PM}$ & 1:05 & 29.15 & 25.65 & -3.5 & 59.35 & 43.36 & -15.99 \\
\hline & May 18, 2012 & $\mathrm{AM}$ & 1:00 & 26.15 & 24.15 & -2 & 57.85 & 66.17 & 8.32 \\
\hline & May 18, 2012 & PM & 1:00 & 30.15 & 27.15 & -3 & 47.59 & 46.39 & -1.2 \\
\hline & May 19, 2012 & $\mathrm{AM}$ & $0: 45$ & 27.15 & 26.15 & -1 & 64.48 & 74.45 & 9.97 \\
\hline & May 19, 2012 & $\mathrm{PM}$ & $0: 30$ & 32.15 & 29.65 & -2.5 & 54.7 & 46.39 & -8.34 \\
\hline & May 20, 2012 & $\mathrm{AM}$ & 1:00 & 26.65 & 24.65 & -2 & 43.97 & 54.7 & 10.73 \\
\hline & May 20, 2012 & PM & $1: 00$ & 31.15 & 26.65 & -4.5 & 51.76 & 52.35 & 0.59 \\
\hline & May 21, 2012 & $\mathrm{AM}$ & 1:00 & 28.15 & 26.15 & -2 & 71.72 & 68.96 & -2.76 \\
\hline & May 21, 2012 & PM & $0: 40$ & 32.15 & 28.65 & -3.5 & 45.78 & 45.18 & -0.6 \\
\hline & May 22, 2012 & $\mathrm{AM}$ & $0: 50$ & 27.15 & 26.65 & -0.5 & 49.39 & 62.21 & 12.21 \\
\hline & May 22, 2012 & PM & $0: 35$ & 30.15 & 28.65 & -1.5 & 45.18 & 38.45 & -6.73 \\
\hline & May 23, 2012 & $\mathrm{AM}$ & $0: 55$ & 29.15 & 26.15 & -3 & 66.17 & 52.35 & -13.82 \\
\hline & May 23, 2012 & PM & $0: 35$ & 30.65 & 29.15 & -1.5 & 25.19 & 23.9 & -1.29 \\
\hline & May 24, 2012 & $\mathrm{AM}$ & $0: 55$ & 29.15 & 27.65 & -1.5 & 37.21 & 40.91 & 3.7 \\
\hline
\end{tabular}

Table 8. Logistic regression model from 1,214 flutter observations of nesting lesser prairie-chicken hens from Roosevelt County, New Mexico, and Cochran, Hockley, Terry, and Yoakum Counties, Texas, U.S.A., 2010, 2012.

\begin{tabular}{|c|c|c|c|c|c|c|}
\hline Predictor & $\beta$ & $S E^{\beta}$ & $\begin{array}{c}\text { Wald's } \\
\chi^{2}\end{array}$ & $d f$ & $\boldsymbol{P}$ & $\mathbf{e}^{\beta}$ \\
\hline Intercept & -3.44 & 0.54 & 40.32 & 1 & $<0.0001$ & $\mathrm{~N} / \mathrm{A}$ \\
\hline $\begin{array}{l}\text { Random } \\
\text { temperature }\end{array}$ & 0.17 & 0.01 & 129.53 & 1 & $<0.0001$ & 1.18 \\
\hline Random RH & -0.02 & 0.004 & 49.95 & 1 & $<0.0001$ & 0.97 \\
\hline \multicolumn{3}{|c|}{ Test } & $\chi^{2}$ & & $d f$ & $P$ \\
\hline \multicolumn{7}{|c|}{ Overall model evaluation } \\
\hline \multicolumn{3}{|c|}{ Likelihood ratio test } & 655.99 & & 2 & $<0.0001$ \\
\hline \multicolumn{3}{|l|}{ Score test } & 514.74 & & 2 & $<0.0001$ \\
\hline \multicolumn{2}{|l|}{ Wald test } & & 289.4 & & 2 & $<0.0001$ \\
\hline \multicolumn{7}{|c|}{ Goodness-of-fit test } \\
\hline \multicolumn{3}{|c|}{ Hosmer and Lemeshow } & 67.33 & & 8 & $<0.0001$ \\
\hline
\end{tabular}




\section{Assessment of 10-Year Dataset}

\section{Nesting Ecology}

\section{Nest-Site Selection}

We located 205 nests from 169 female lesser prairiechickens from 2001 to 2010 . We eliminated 23 nests from analysis because they were either located on an adjacent ranch that was treated with tebuthiuron in 2009 or because we were unable to accurately assign a habitat treatment type. Of the 182 nests, 73 (40 percent) nests were located in NT-G areas, 36 (20 percent) were located in NT-NG areas, 53 (29 percent) were located in T-G areas, and 20 (11 percent) were located in T-NG areas (table 9).

Because the study area was not grazed for 2 years after herbicide treatment, all nests located in an herbicide-treated area were labeled as T-NG. Nests that occurred on neighboring ranches were categorized as grazed because these areas were grazed in 2001-2. More nests were located in grazed pastures compared to not-grazed pastures 3-5 years after treatment. By the year 2006 ( 5 growing seasons after treatment) there were only two small noticeable patterns: more nests were located in T-G areas and no nests were located in T-NG areas (table 9).

\section{Nest Site Selection 2001-2}

We used 18 nests from one lek of capture (lek " 8 ") for this analysis. The total available nesting habitat for this lek was 1,132 hectares. Not-treated and grazed areas (628 ha) and T-NG (312 ha) were more abundant compared to NT-NG areas (191 ha). Twelve nests (67 percent) were located in NT-G areas, 2 (17 percent) were located in NT-NG areas,

Table 9. Number of lesser prairie-chicken nests located in each treatment type for each year of study in Roosevelt County, New Mexico, 2001-10.

[NT-G, not treated and grazed; NT-NG, not treated and not grazed; T-G, treated and grazed; T-NG, treated and not grazed]

\begin{tabular}{lccccc}
\hline Year & NT-G & NT-NG & T-G & T-NG & Total \\
\hline 2001 & 8 & 3 & N/A & 7 & 18 \\
2002 & 19 & 4 & N/A & 9 & 32 \\
2003 & 14 & 5 & 5 & 0 & 24 \\
2004 & 4 & 1 & 1 & 1 & 7 \\
2005 & 15 & 3 & 5 & 0 & 23 \\
2006 & 5 & 6 & 5 & 0 & 16 \\
2007 & 1 & 3 & 7 & 0 & 11 \\
2008 & 3 & 1 & 15 & 1 & 20 \\
2009 & 2 & 6 & 5 & 0 & 13 \\
2010 & 2 & 4 & 10 & 2 & 18 \\
Total & 73 & 36 & 53 & 20 & 182 \\
\hline
\end{tabular}

and 2 (17 percent) were located in T-NG areas. Of the 100 randomly placed points, 57 (57 percent) were located in NT-G areas, 25 (25 percent) were located in NT-NG areas, and 18 (18 percent) points were located in T-NG areas; lesser prairiechickens did not use treatment types disproportionately to what was expected $\left(x^{2}=0.81, P=0.66\right)$.

\section{Nest Site Selection 2003-10}

We used 84 nests from five leks of capture for this analysis (table 10). The total available nesting habitat for radio-tagged lesser prairie-chickens for each lek was 1,132 hectares. The amount of available habitat varied by individual lek, but overall NT-G and T-G areas were more common compared to NT-NG and T-NG areas (table 10).

Table 10. Available nesting habitat, proportion of nests located in each treatment type, and the proportion of expected use for 100 randomly placed locations for five individual leks in Roosevelt County, New Mexico, 2003-10.

[NT-G, not treated and grazed; NT-NG, not treated and not grazed; T-G, treated and grazed; T-NG, treated and not grazed; *, the NT-G areas for this lek were all found within untreated dune systems on the study area]

\begin{tabular}{rcrrr}
\hline \multirow{2}{*}{ Lek } & \multicolumn{4}{c}{ Available hectares } \\
\cline { 2 - 5 } & NT-G & NT-NG & \multicolumn{1}{c}{ T-G } & \multicolumn{1}{c}{ T-NG } \\
\hline 1 & 591.59 & 243.44 & 197.75 & 99.22 \\
4 & 1,132 & 0.01 & 0.01 & 0.01 \\
5 & 839.6 & 0.01 & 293.39 & 0.01 \\
7 & $8.03^{*}$ & 0.01 & $1,024.87$ & 99.1 \\
17 & 765.77 & 244.02 & 100.11 & 22.9
\end{tabular}

\begin{tabular}{|c|c|c|c|c|c|}
\hline \multirow{2}{*}{ Lek } & \multicolumn{5}{|c|}{ Used proportion } \\
\hline & $n$ & NT-G & NT-NG & T-G & T-NG \\
\hline 1 & 13 & 0.14 & 0.5 & 0.14 & 0.14 \\
\hline 4 & 16 & 0.56 & 0.06 & 0.38 & 0 \\
\hline 5 & 15 & 0.73 & 0.06 & 0.2 & 0 \\
\hline 7 & 28 & 0.32 & 0.04 & 0.64 & 0.04 \\
\hline 17 & 12 & 0.08 & 0.67 & 0.25 & 0 \\
\hline
\end{tabular}

\begin{tabular}{rclllllrc}
\hline \multirow{2}{*}{ Lek } & \multicolumn{9}{c}{ Expected proportion } & \multirow{2}{*}{$\boldsymbol{\chi}^{2}$} & $\boldsymbol{p}$ \\
\cline { 2 - 6 } & & \multicolumn{1}{c}{$\boldsymbol{n}$} & NT-G & NT-NG & T-G & T-NG & & \\
\hline 1 & 100 & 0.53 & 0.31 & 0.08 & 0.08 & 7.43 & 0.05 \\
4 & 100 & 1 & 0 & 0 & 0 & 99.83 & $>0.001$ \\
5 & 100 & 0.79 & 0 & 0.21 & 0 & 4.85 & 0.08 \\
7 & 100 & 0 & 0 & 0.93 & 0.07 & 276.67 & $>0.001$ \\
17 & 100 & 0.63 & 0.29 & 0.08 & 0 & 14.97 & $>0.001$ \\
\hline
\end{tabular}


The proportion of observed nests within each treatment type varied by lek, and there were fewer nests observed in T-NG areas across the five leks. Otherwise, there were no noticeable trends for the proportion of observed nests within each treatment (table 10). The expected number of nests within each treatment followed the same pattern as the total amount of habitat available for each lek, as there were fewer numbers of expected nests in NT-NG and T-NG areas (table 10). Lesser prairie-chicken hens used treatments disproportionately to what was expected for of the 5 leks whereas they used treatments in proportion to what was expected for 1 lek.

Treated and not-grazed was the only treatment that was used in proportion to what was expected within the four leks that suggested selection (table 11). Otherwise, there were no

Table 11. The proportion of nests observed for each treatment (TRT), 95 percent confidence interval for each observed proportion, the expected proportion for each treatment, and selection assessment for four leks in Roosevelt County, New Mexico, 2003-10. We excluded lek 5 from this assessment because nests were placed within treatments in proportion to what was expected.

[NT-G, not treated and grazed; NT-NG, not treated and not grazed; T-G, treated and grazed; T-NG, treated and not grazed]

\begin{tabular}{|c|c|c|c|c|c|}
\hline Lek & TRT & Observed & $\begin{array}{c}95 \% \\
\text { Confidence } \\
\text { interval }\end{array}$ & Expected & Outcome \\
\hline \multirow[t]{4}{*}{1} & NT-G & 0.14 & $0.08-0.20$ & 0.53 & Used less \\
\hline & NT-NG & 0.5 & $0.41-0.59$ & 0.31 & No difference \\
\hline & $\mathrm{T}-\mathrm{G}$ & 0.14 & $0.08-0.20$ & 0.08 & No difference \\
\hline & T-NG & 0.14 & $0.08-0.20$ & 0.08 & No difference \\
\hline \multirow[t]{4}{*}{4} & NT-G & 0.56 & $0.48-0.64$ & 1 & Used less \\
\hline & NT-NG & 0.06 & $0.02-0.10$ & 0 & No difference \\
\hline & T-G & 0.38 & $0.30-0.46$ & 0 & Used more \\
\hline & $\mathrm{T}-\mathrm{NG}$ & 0 & $0.00-0.00$ & 0 & No difference \\
\hline \multirow[t]{4}{*}{7} & NT-G & 0.32 & $0.24-0.40$ & 0 & Used more \\
\hline & NT-NG & 0.04 & $0.01-0.07$ & 0 & Used more \\
\hline & $\mathrm{T}-\mathrm{G}$ & 0.64 & $0.56-0.72$ & 0.93 & Used less \\
\hline & T-NG & 0.04 & $0.01-0.07$ & 0.07 & No difference \\
\hline \multirow[t]{4}{*}{17} & NT-G & 0.08 & $0.04-0.12$ & 0.63 & Used less \\
\hline & NT-NG & 0.67 & $0.59-0.75$ & 0.29 & Used more \\
\hline & $\mathrm{T}-\mathrm{G}$ & 0.25 & $0.18-0.32$ & 0.08 & Used more \\
\hline & T-NG & 0 & $0.00-0.00$ & 0 & No difference \\
\hline
\end{tabular}

noticeable selection patterns for each treatment type among the four leks of interest (table 11).

\section{Nest Survival}

We assessed nest survival for 181 nests (103 nests from 2001-05 and 78 from 2006-10). Based on model selection criteria, there was no evidence of differences in daily survival rates across treatment types (table 12). Model-averaged results suggested the probability of daily nest survival across habitat plots was 0.95 (SE 0.003). Thus, the probability of a nest surviving the 28-day incubation period was 0.24 (that is, $\left.0.95^{28}\right)$.

Table 12. Output from five a priori models used to estimate daily nest survival rates for 181 lesser prairie-chicken nests in Roosevelt County, New Mexico, U.S.A., 2001-10.

\begin{tabular}{lccc}
\hline \multicolumn{1}{c}{ Model } & AIC $_{\mathbf{c}}$ & $\begin{array}{c}\text { Change } \\
\text { in AIC }_{\mathbf{c}}\end{array}$ & $\begin{array}{c}\text { AIC }_{\mathbf{c}} \\
\text { weights }\end{array}$ \\
\hline All treatments same & $1,118.34$ & 0 & 0.39 \\
Grazing & $1,119.29$ & 0.95 & 0.24 \\
Herbicide & $1,120.13$ & 1.79 & 0.16 \\
Reciprocal & $1,120.17$ & 1.83 & 0.15 \\
All treatments different & $1,122.53$ & 4.18 & 0.04 \\
\hline \multicolumn{1}{c}{ Model } & & & \\
& Model & & \\
\hline All treatments same & 1 & 1 & $1,116.34$ \\
Grazing & 0.62 & 2 & $1,115.29$ \\
Herbicide & 0.4 & 2 & $1,116.13$ \\
Reciprocal & 0.39 & 2 & $1,116.17$ \\
All treatments different & 0.12 & 4 & $1,114.51$ \\
\hline
\end{tabular}




\section{Vegetation Response}

\section{Precipitation}

The highest-ranking index for all precipitation indices was winter precipitation (table 13). The effect of precipitation was statistically significant on soil moisture and percent vegetative composition. The linear relationship between soil moisture and percent composition was marginally biologically relevant because these relations had low $r^{2}$ values. The relations between precipitation and soil moisture as well as precipitation and percent composition were negative.

\section{Soil Moisture}

Winter precipitation from October to March was the highest ranked precipitation measure for soil moisture in April (table 13). Winter precipitation had a significant effect in the ANCOVA $\left(F_{8,396}=541.91, P<0.0001\right.$; table 14$)$; however, even though the slope for winter precipitation was statistically significant, it offered little ecological explanatory ability $\left(r^{2}=0.12 ; F_{1,430}=59.36, P<0.001\right.$; fig. $8 A$ ). Plots treated with tebuthiuron had 16 percent more soil moisture in April than those that were not treated $\left(F_{1,396}=105.04, P<0.0001\right.$; fig. $\left.9 A\right)$. There was also a grazing effect $\left(F_{1,396}=7.67, P=0.006\right)$ such that soil moisture increased by 4 percent in grazed areas compared to not-grazed areas. There was no herbicide and grazing interaction effect $\left(F_{1,428}=0.16, P=0.69\right)$.
Table 13. List of ranked Akaiki Information Criterion (AIC) models for precipitation, AIC $_{c^{\prime}}$ change in $\mathrm{AIC}_{c^{\prime}}$ and $\mathrm{AIC}_{\mathrm{c}}$ weights for soil moisture in April and June. Data were collected in 16 experimental plots consisting of the combinations of (1) tebuthiuron (herbicide) treated and grazed, (2) tebuthiuron treated and not grazed, (3) nontebuthiuron treated and grazed, and (4) nontebuthiuron treated and not grazed in eastern New Mexico, 2000-10.

\begin{tabular}{|c|c|c|c|c|c|}
\hline $\begin{array}{l}\text { Model } \\
\text { rank }\end{array}$ & $\begin{array}{l}\text { Precipitation } \\
\text { index }\end{array}$ & $K$ & AIC $_{c}$ & $\begin{array}{l}\text { Change } \\
\text { in AIC }\end{array}$ & $\begin{array}{c}\text { AlC }_{c} \\
\text { weights }\end{array}$ \\
\hline \multicolumn{6}{|c|}{ Soil moisture in April } \\
\hline 1 & Winter II $^{1}$ & 4 & $3,733.30$ & 0 & 1 \\
\hline 2 & Winter $I^{2}$ & 4 & $3,751.60$ & -18.3 & 0 \\
\hline 3 & Growing season ${ }^{3}$ & 4 & $3,792.60$ & -59.3 & 0 \\
\hline 4 & Annual season ${ }^{4}$ & 4 & $3,798.40$ & -65.1 & 0 \\
\hline \multicolumn{6}{|c|}{ Soil moisture in June } \\
\hline 1 & Winter I & 4 & $3,490.50$ & 0 & 0.578 \\
\hline 2 & Winter II & 4 & $3,491.20$ & -0.7 & 0.407 \\
\hline 3 & Growing season & 4 & $3,497.90$ & -7.4 & 0.014 \\
\hline 4 & Annual season & 4 & $3,503.50$ & -13 & 0.001 \\
\hline
\end{tabular}

\footnotetext{
${ }^{1}$ Winter II is October-March.

${ }^{2}$ Winter I is November-March.

${ }^{3}$ Growing season is April-October.

${ }^{4}$ Annual season is April-March.
}

Table 14. List of top ranked Akaiki Information Criterion (AIC) models for precipitation, W, precipitation effect's $F$ and $P$ values, $r^{2}$, and trend of precipitation regression for soil moisture and plant composition. Data were collected in 16 experimental plots consisting of the combinations of (1) tebuthiuron (herbicide) treated and grazed, (2) tebuthiuron treated and not grazed, (3) nontebuthiuron treated and grazed, and (4) tebuthiuron treated and not grazed in eastern New Mexico, 2000-10.

\begin{tabular}{lllllll}
\hline & $\begin{array}{c}\text { Top ranked } \\
\text { model }\end{array}$ & W & \multicolumn{1}{c}{$\boldsymbol{F}$} & $\boldsymbol{P}$ & $\boldsymbol{r}^{2}$ & Trend $^{2}$ \\
\hline Soil moisture in April & Winter II & 1 & $F_{8,396}=541.91$ & $P<0.0001$ & 0.12 & - \\
Soil moisture in June & Winter I & 0.578 & $F_{8,360}=503.30$ & $P<0.0001$ & 0.01 & - \\
Presence of sand shinnery oak & Winter II & 0.987 & $F_{3,144}=4.60$ & $P=0.004$ & 0.03 & - \\
Presence of bluestem species & Winter II & 0.646 & $F_{9,108}=39.25$ & $P<0.0001$ & 0.06 & - \\
\hline
\end{tabular}

\footnotetext{
${ }^{1}$ Winter II is October to March; Winter I is November to March; Growing season is April to March.

${ }^{2}$ Trend of precipitation regression.
} 

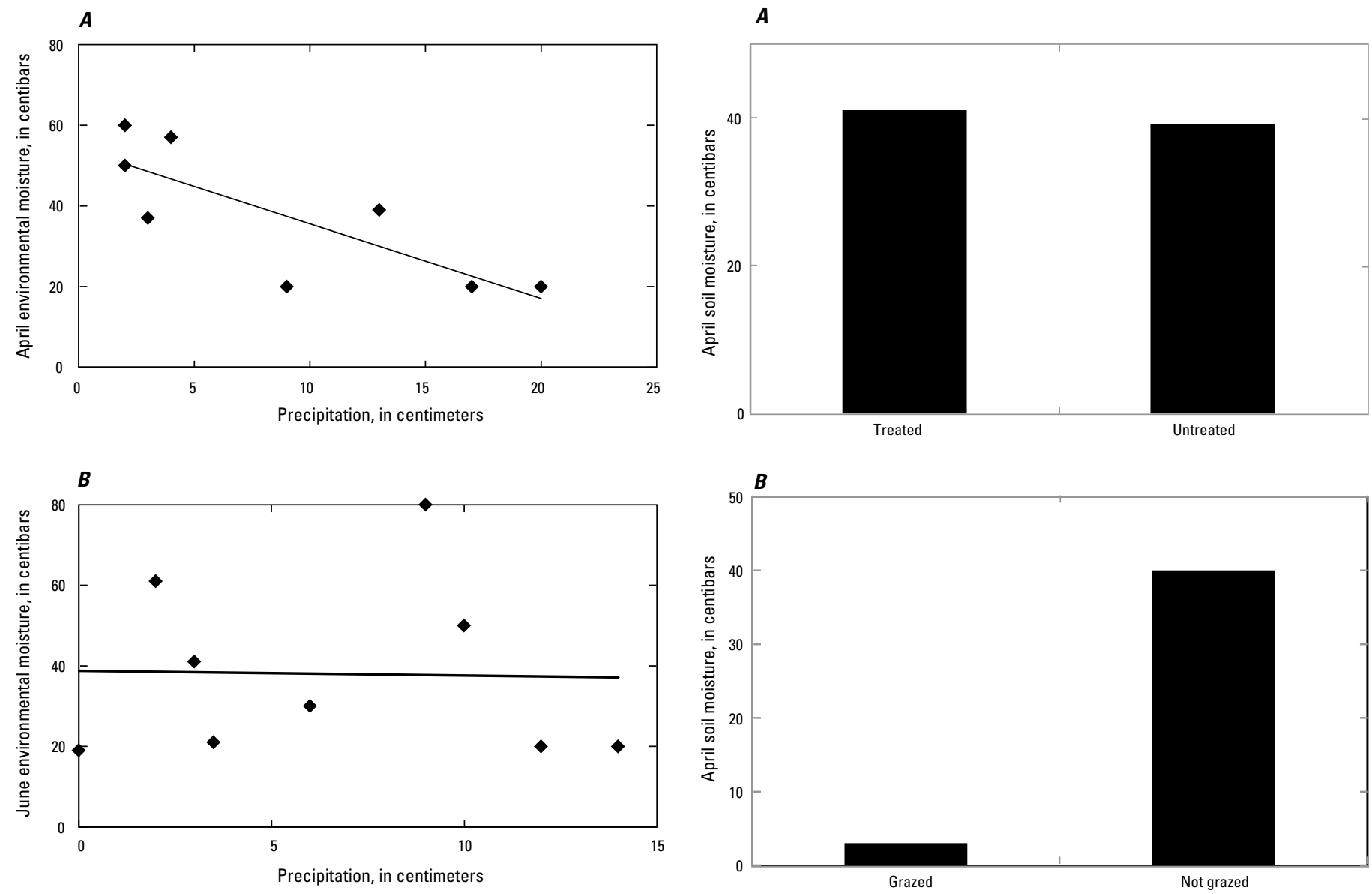

Figure 8. Regression of environmental moisture and winter precipitation for April, $A$, and June, $B$, from a study of sand shinnery oak-grass communities in eastern New Mexico, 2002-10.

Figure 9. Soil moisture in April as a dependent variable in models testing the effect of herbicide, $A$, and grazing treatments, $B$, in sand shinnery oak grass communities in Roosevelt County, New Mexico, 2001-10 (missing data for 2002). 
Winter precipitation from November to March was the highest ranked precipitation measure for soil moisture in June (table 13). Winter precipitation was a significant factor in the $\operatorname{ANCOVA}\left(F_{8,360}=503.30, P<0.0001\right.$; table 14). The slope between winter precipitation and soil moisture in June was statistically significant, but there was no explanatory power in the relationship $\left(r^{2}=0.01 ; F_{1,391}=3.97, P=0.05\right.$; fig. $\left.8 B\right)$. Soil moisture in June was 17 percent greater in plots treated with tebuthiuron $\left(F_{1,360}=71.89, P<0.0001\right.$; fig. 10A). There was no grazing effect $\left(F_{1,360}=1.72, P=0.19\right.$; fig. $\left.10 B\right)$, nor was there an herbicide and grazing interaction effect $\left(F_{1,360}=1.03\right.$, $P=0.32$ ) for June soil moisture.

\section{Percentage of Composition}

We used winter precipitation from November to March in the MANCOVA model for community composition $\left(F_{1,120}\right.$ $=6.63, P=0.0001$; table 15); however, for each dependent variable, the winter precipitation index did not have a significant effect: grass $-r^{2}=0.007, F_{1,120}=1.01, P=0.32$; shrub $-r^{2}=0.008, F_{1,120}=1.22, P=0.27$; forb $-r^{2}=0.0002$, $F_{1,120}=0.04, P=0.85$; litter $-r^{2}=0.005, F_{1,120}=0.68, P=$ 0.41 ; and bare ground $-r^{2}=0.0001, F_{1,120}=0.01, P=0.91$ (table 15).
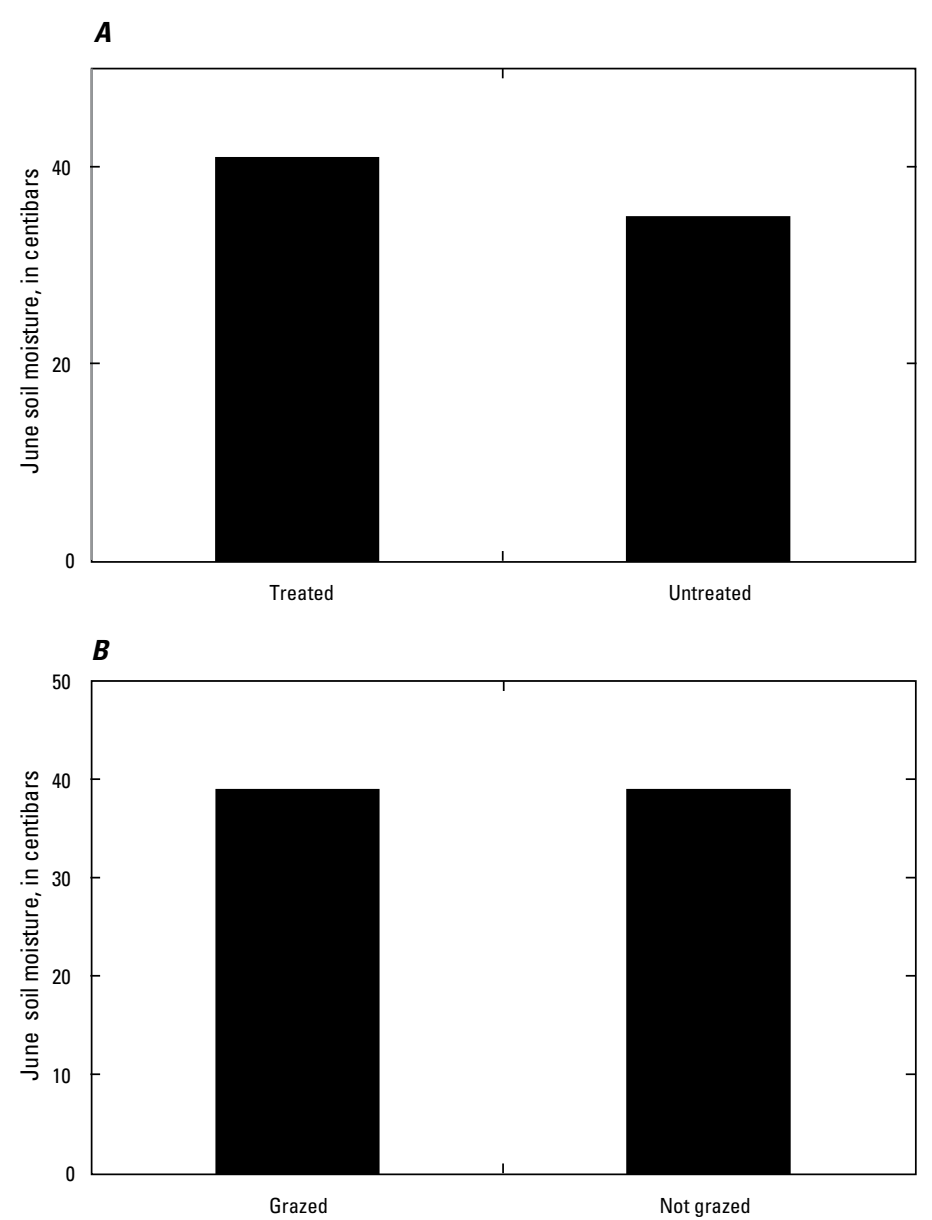

Figure 10. Soil moisture in June as a dependent variable in models testing the effect of herbicide, $A$, and grazing treatments, $B$, in sand shinnery oak grass communities in Roosevelt County, New Mexico, 2001-10 (missing data for 2002 and 2008). The mean values for treated and not treated areas differed $(P<0.05)$.

Table 15. Summary of percent cover variables (grass, shrub, forb, litter, and bare ground) and their relationship with winter precipitation index, which was selected for the MANOVA following the trends of other plant variables. Data are from 16 experimental plots consisting of the combinations of (1) tebuthiuron (herbicide) treated and grazed, (2) tebuthiuron treated and not grazed, (3) nontebuthiuron treated and grazed, and (4) nontebuthiuron treated and not grazed in eastern New Mexic0, 2002-10.

\begin{tabular}{lcccc}
\hline & $\begin{array}{c}\text { Top rank } \\
\text { precipitation index }\end{array}$ & $\boldsymbol{F}$ & $\boldsymbol{P}$ & $\boldsymbol{r}^{2}$ \\
\hline Overall percent cover & Winter II $^{1}$ & $F_{1,120}=6.63$ & $P<0.0001$ & Trend \\
\hline Grass & $F_{1,120}=1.01$ & $P=0.3168$ & 0.0071 & - \\
Shrub & $F_{1,120}=1.22$ & $P=0.2722$ & 0.0085 & - \\
Forb & $F_{1,120}=0.04$ & $P=0.8511$ & 0.0002 & - \\
Litter & $F_{1,120}=0.68$ & $P=0.41$ & 0.0048 & 0.0001 \\
Bare ground & $F_{1,120}=0.01$ & $P=0.91$ & - \\
\hline
\end{tabular}

\footnotetext{
${ }^{1}$ Winter II is October to March.
} 
The results from the MANCOVA suggested significant herbicide $\left(F_{5,124}=282.2, P<0.0001\right)$ and grazing effects $\left(F_{5,124}=11.14, P<0.0001\right)$, but no interaction effect $\left(F_{5,124}=0.33, P=0.89\right)$ (table 16). We tested herbicide and grazing treatments for each dependent variable by using individual ANCOVAs. An effect of herbicide was found for percentage of shrub cover (fig. 11A), grass (fig. 12A), forb (fig. 13A), and litter (fig. 14A). Grazing only had an effect on litter (fig. 14B) and bare ground (fig. 15B). Shrubs were 117 percent greater in untreated plots than those treated with herbicide. Consequently, grasses increased by 149 percent and forbs increased by 257 percent in treated areas compared to untreated areas. Litter decreased by 17 percent in treated areas as compared to untreated areas. There was 13 percent less litter and 28 percent more bare ground in grazed than notgrazed pastures.

Table 16. Overall MANCOVA results for percent cover and individual ANCOVA results for percentage of cover with associated $F$ and $P$ values. Data are from 16 experimental plots consisting of the combinations of (1) tebuthiuron (herbicide) treated and grazed, (2) tebuthiuron treated and not grazed, (3) nontebuthiuron treated and grazed, and (4) nontebuthiuron treated and not grazed in eastern New Mexico, 2000-10.

\begin{tabular}{lccc}
\hline & $\begin{array}{c}\text { Wilks' } \\
\text { lambda }\end{array}$ & $\boldsymbol{F}(\mathbf{d f})$ & $\boldsymbol{P}$ \\
\hline Herbicide & 0.081 & $282.2(5,124)$ & $<0.0001$ \\
Grazing & 0.69 & $11.14(5,124)$ & $<0.0001$ \\
Herbicide*grazing & 0.99 & $0.33(5,124)$ & 0.89
\end{tabular}

\begin{tabular}{|c|c|c|c|c|c|}
\hline \multirow{2}{*}{$\begin{array}{c}\text { Percent } \\
\text { cover }\end{array}$} & \multirow{2}{*}{ N/A } & \multicolumn{2}{|c|}{ Herbicide } & \multicolumn{2}{|c|}{ Grazed } \\
\hline & & $\boldsymbol{F}$ & $\boldsymbol{P}$ & $\boldsymbol{F}$ & $\boldsymbol{P}$ \\
\hline Grass & N/A & 235.91 & $<0.0001$ & 0.05 & 0.83 \\
\hline Shrub & $\mathrm{N} / \mathrm{A}$ & 238.75 & $<0.0001$ & 0.44 & 0.51 \\
\hline Forb & N/A & 64.38 & $<0.0001$ & 0 & 0.96 \\
\hline Litter & N/A & 17.92 & $<0.0001$ & 7.28 & 0.0078 \\
\hline Bare ground & N/A & 2.42 & 0.14 & 24.59 & 0.0003 \\
\hline
\end{tabular}
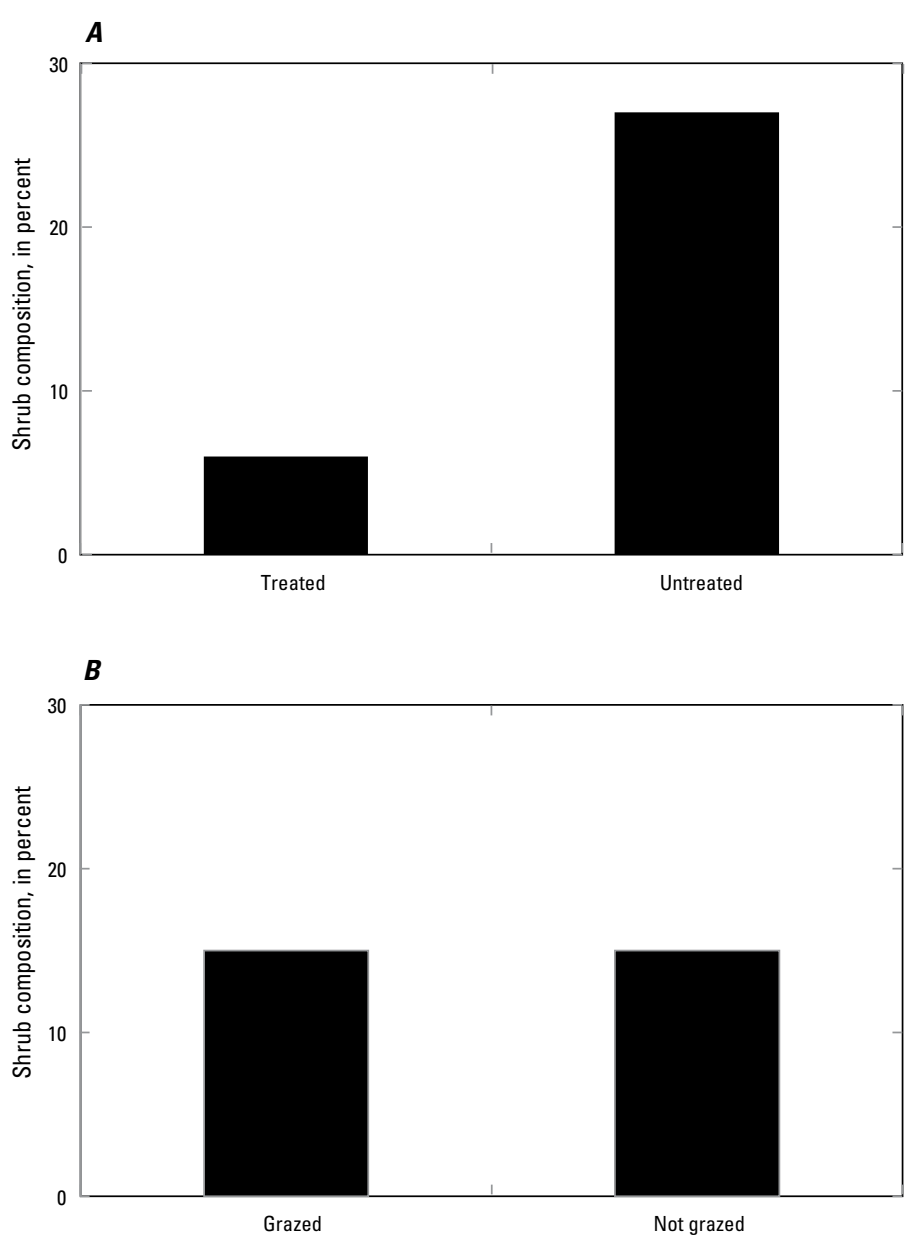

Figure 11. Percentage of composition of shrubs as a dependent variable in models testing the effect of herbicide, $A$, and grazing treatments, $B$, in sand shinnery oak grass communities in Roosevelt County, New Mexico, 2002-10. The mean values for treated and not treated areas differed $(P<0.05)$. 

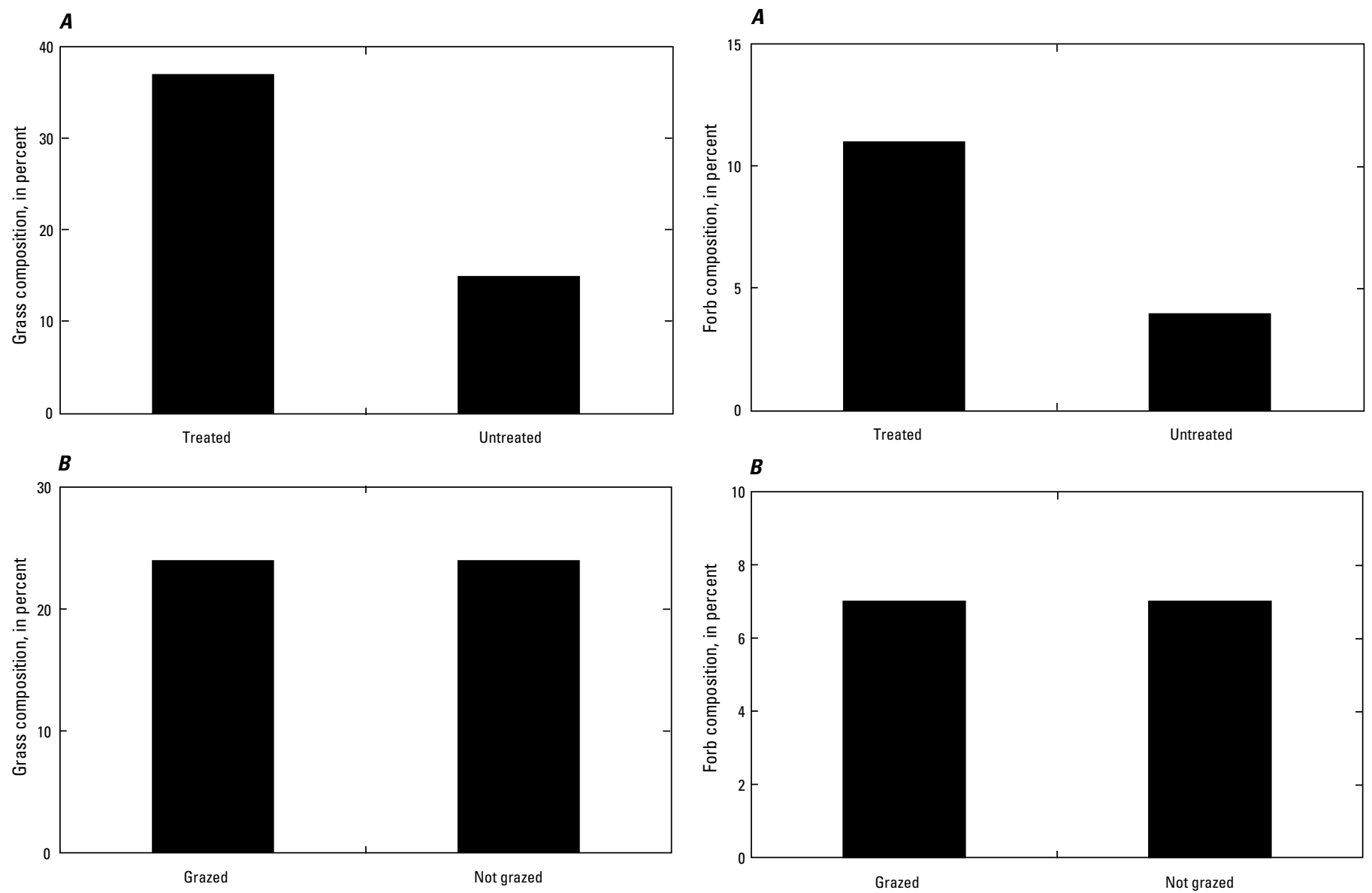

Figure 12. Percentage of composition of grass as a dependent variable in models testing the effect of herbicide, $A$, and grazing treatments, $B$, in sand shinnery oak grass communities in Roosevelt County, New Mexic0, 2002-10. The mean values for treated and not treated areas differed $(P<0.05)$.

Figure 13. Percentage of composition of forbs as a dependent variable in models testing the effect of herbicide, $A$, and grazing treatments, $B$, in sand shinnery oak grass communities in Roosevelt County, New Mexico, 2002-10. The mean values for treated and not treated areas differed $(P<0.05)$. 

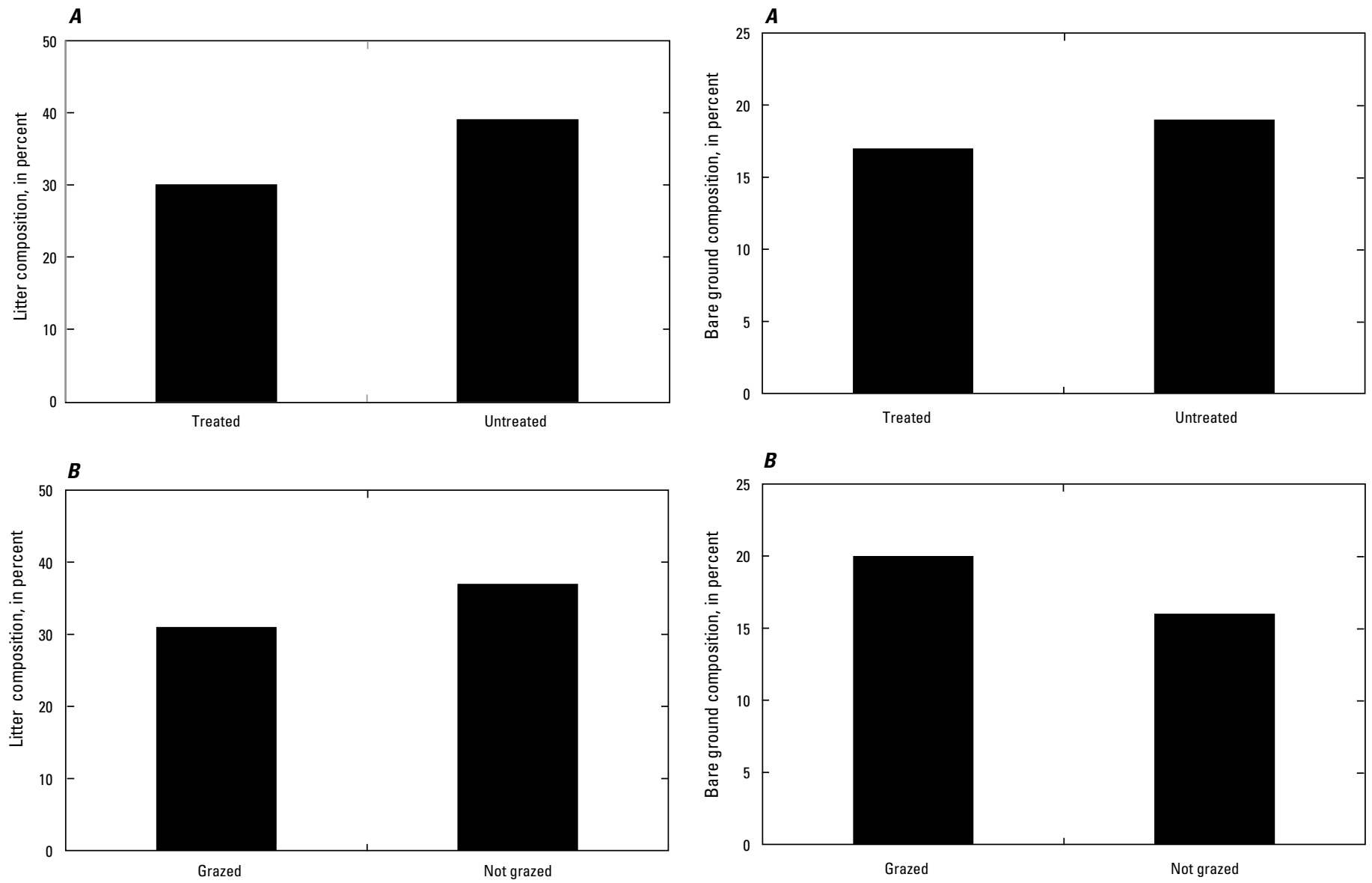

Figure 14. Percentage of composition of litter as a dependent variable in models testing the effect of herbicide, $A$, and grazing treatments, $B$, in sand shinnery oak grass communities in Roosevelt County, New Mexico, 2002-10. The mean values for treated and not treated areas differed $(P<0.05)$.

Figure 15. Percentage of composition of bare ground as a dependent variable in models testing the effect of herbicide, $A$, and grazing treatments, $B$, in sand shinnery oak grass communities in Roosevelt County, New Mexico, 2002-10. The mean values for graze and not grazed areas differed $(P<0.05)$. 
Winter precipitation from October to March was the highest ranked precipitation index relative to the occurrence of sand shinnery oak (table 17). There was a significant precipitation effect on presence of sand shinnery oak $\left(F_{3,144}=\right.$ $4.60, P=0.004$; table 14$)$; however, despite a significant slope, the relationship between sand shinnery oak occurrence and precipitation index was weak $\left(r^{2}=0.03\right.$; table $14 ; F_{1,158}=5.46$, $P=0.02$; fig. 16A). Treated areas had 91 percent less sand oak than untreated areas $\left(F_{1,12}=744.68, P<0.0001\right.$; fig. $17 A$; table 18). We found no evidence of a grazing effect $\left(F_{1,12}=\right.$ $0.23, P=0.64$; fig. $17 B$; table 18 ), but a possible, if marginal, herbicide and grazing interaction effect $\left(F_{1,12}=4.33, P=0.06\right.$; table 18) on the occurrence of sand shinnery oak.

Table 17. List of ranked Akaiki Information Criterion (AIC) models for precipitation, $\mathrm{AlC}_{c^{\prime}}$ change in $\mathrm{AIC}_{\mathrm{c}^{\prime}}$ and $\mathrm{AIC}_{\mathrm{c}}$ weights for presence of sand shinnery oak and sand bluestem species. Data were collected in 16 experimental plots consisting of the combinations of (1) tebuthiuron (herbicide) treated and grazed, (2) tebuthiuron treated and not grazed, (3) nontebuthiuron treated and grazed, and (4) nontebuthiuron treated and not grazed in eastern New Mexico, 2001-10.

\begin{tabular}{|c|c|c|c|c|c|}
\hline $\begin{array}{c}\text { Model } \\
\text { Rank }\end{array}$ & Model & $\boldsymbol{K}$ & AIC $_{c}$ & $\begin{array}{l}\text { Change } \\
\text { in AIC }_{c}\end{array}$ & $\begin{array}{c}\text { AlC }_{c} \\
\text { weights }\end{array}$ \\
\hline \multicolumn{6}{|c|}{ Presence of sand shinnery oak } \\
\hline 1 & Winter II $^{1}$ & 4 & $1,378.60$ & 0 & 0.987 \\
\hline 2 & Winter $I^{2}$ & 4 & $1,387.90$ & -9.3 & 0.009 \\
\hline 3 & Growing season ${ }^{3}$ & 4 & $1,390.30$ & -11.7 & 0.003 \\
\hline 4 & Annual season ${ }^{4}$ & 4 & $1,392.20$ & -13.6 & 0.001 \\
\hline \multicolumn{6}{|c|}{ Presence of bluestem species } \\
\hline 1 & Winter II $^{1}$ & 4 & 947.2 & 0 & 0.646 \\
\hline 2 & Winter $\mathrm{I}^{2}$ & 4 & 949.1 & -1.9 & 0.251 \\
\hline 3 & Growing season ${ }^{3}$ & 4 & 951.2 & -4 & 0.087 \\
\hline 4 & Annual season ${ }^{4}$ & 4 & 954.5 & -7.3 & 0.017 \\
\hline
\end{tabular}

${ }^{1}$ Winter II is October-March.

${ }^{2}$ Winter I is November-March.

${ }^{3}$ Growing season is April-October.

${ }^{4}$ Annual season is April-March.
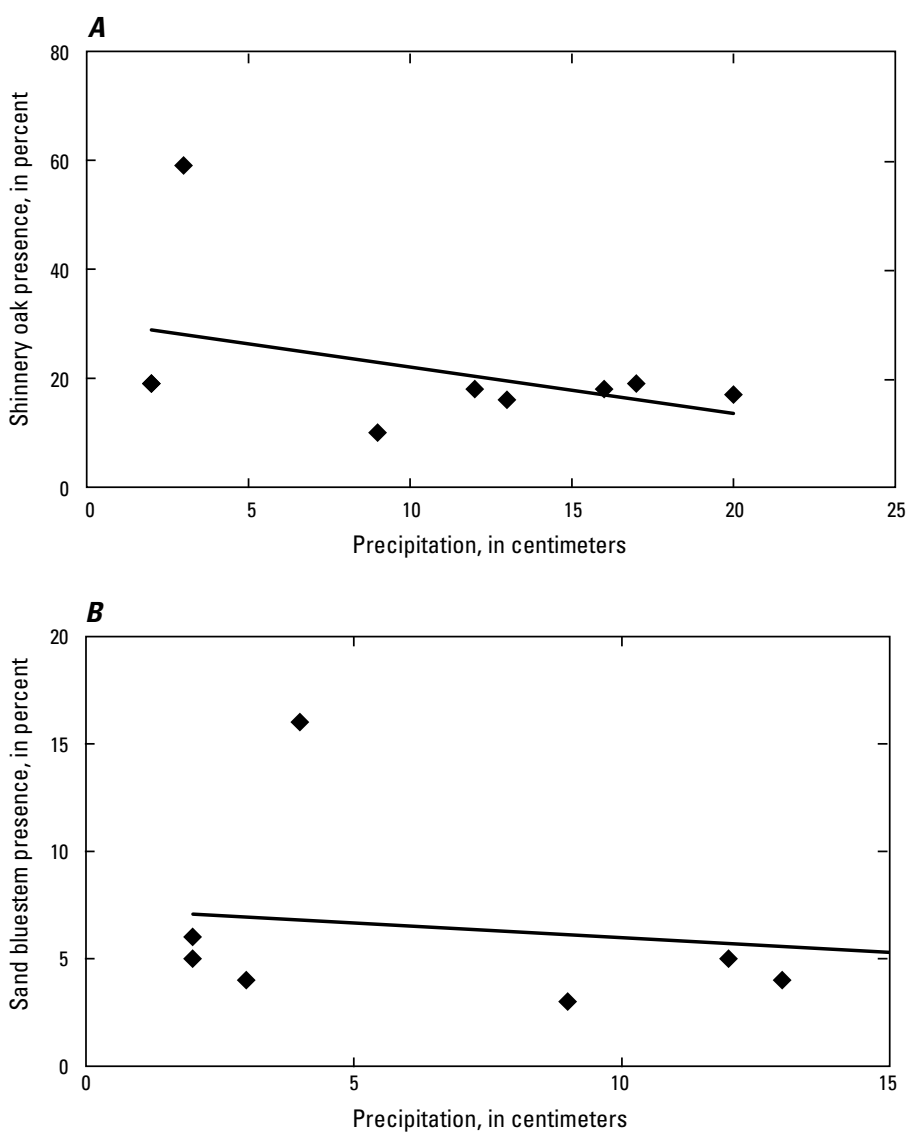

Figure 16. Regression of sand shinnery oak, $A$, and sand bluestem, $B$, presence and winter precipitation from a study of sand shinnery oak grass communities in Roosevelt County, New Mexico, 2002-10. 

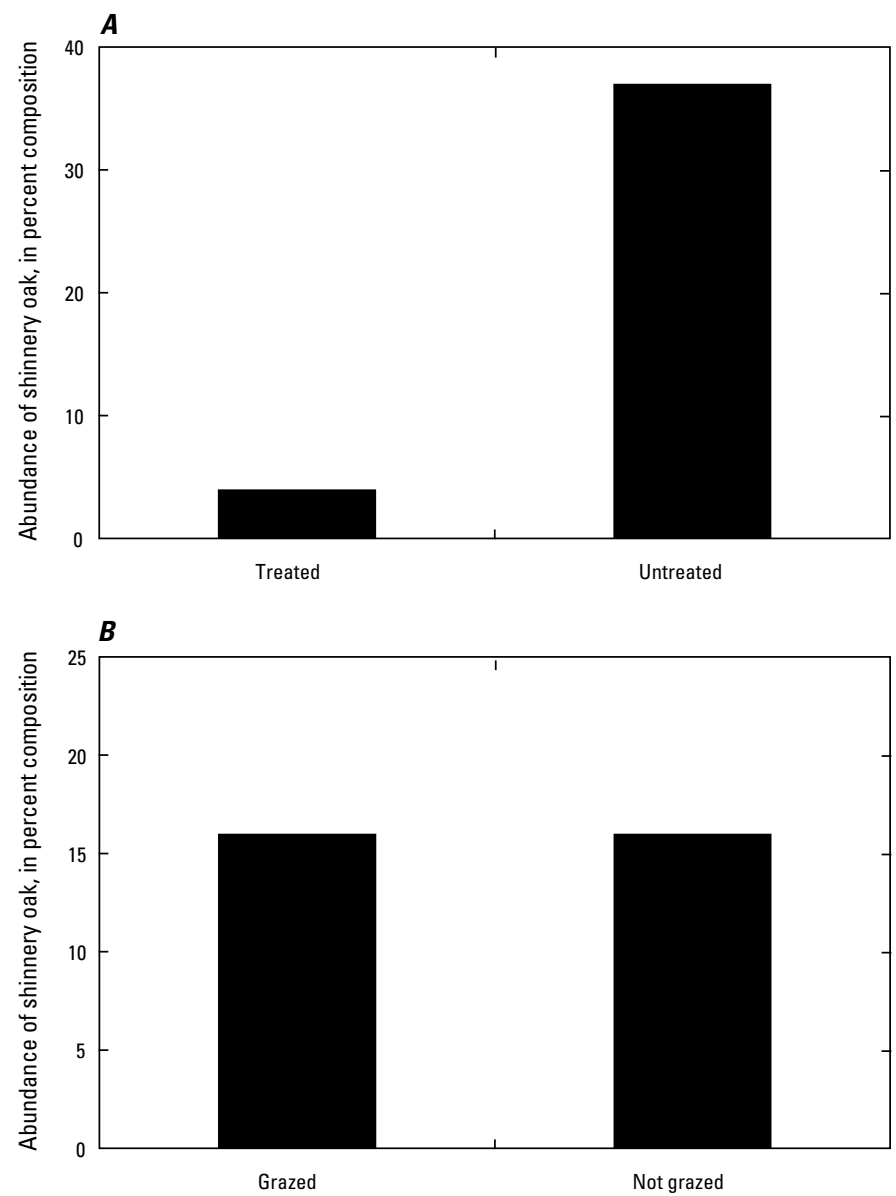

Figure 17. Abundance of sand shinnery oak, in terms of percentage of composition, as a dependent variable in models testing the effect of herbicide, $A$, and grazing treatments, $B$, in sand shinnery oak grass communities in Roosevelt County, New Mexico, 2002-10. The mean values for treated and not treated areas differed $(P<0.05)$.

Table 18. List of herbicide, grazing, and interaction effect for presence of sand shinnery oak and bluestem that were collected in 16 experimental plots consisting of the combinations of (1) tebuthiuron (herbicide) treated and grazed, (2) tebuthiuron treated and not grazed, (3) nontebuthiuron treated and grazed, and (4) nontebuthiuron treated and not grazed in eastern New Mexico, 2001-10.

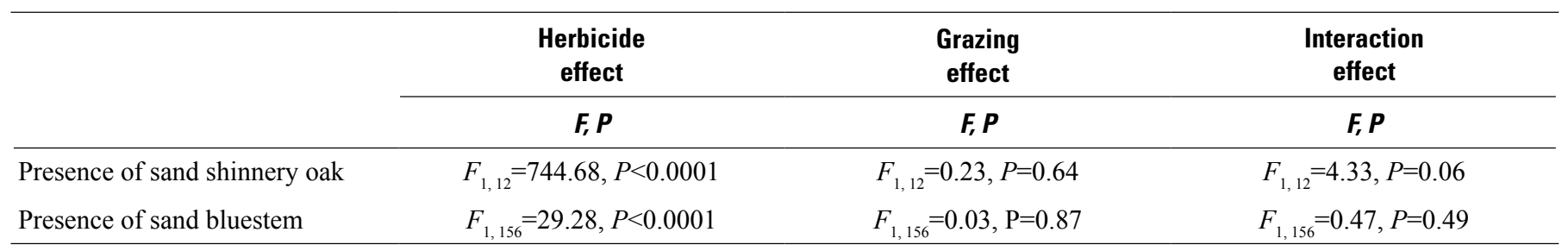


Winter precipitation from October to March was the highest ranked covariate for the occurrence of sand bluestem (table 17). This precipitation index had a significant effect on the occurrence of sand bluestem $\left(F_{9,108}=39.25, P<0.0001\right.$; table 14); however, despite a significant regression slope the precipitation had little predictive influence on sand bluestem ( $\mathrm{r}^{2}=0.06$; table $14 ; F_{1,158}=9.24, P=0.003$; fig. $\left.16 B\right)$. There was an herbicide effect $\left(F_{1,156}=29.28, P<0.0001\right.$; fig. $18 A$; table 18) such that the treated pastures had 118 percent more sand bluestem than those that were not treated. There was no grazing effect $\left(F_{1,156}=0.03, P=0.87\right.$; fig. $18 B$; table 18$)$, nor herbicide and grazing interaction effect $\left(F_{1,156}=0.47, P=\right.$ 0.49 ; table 18).
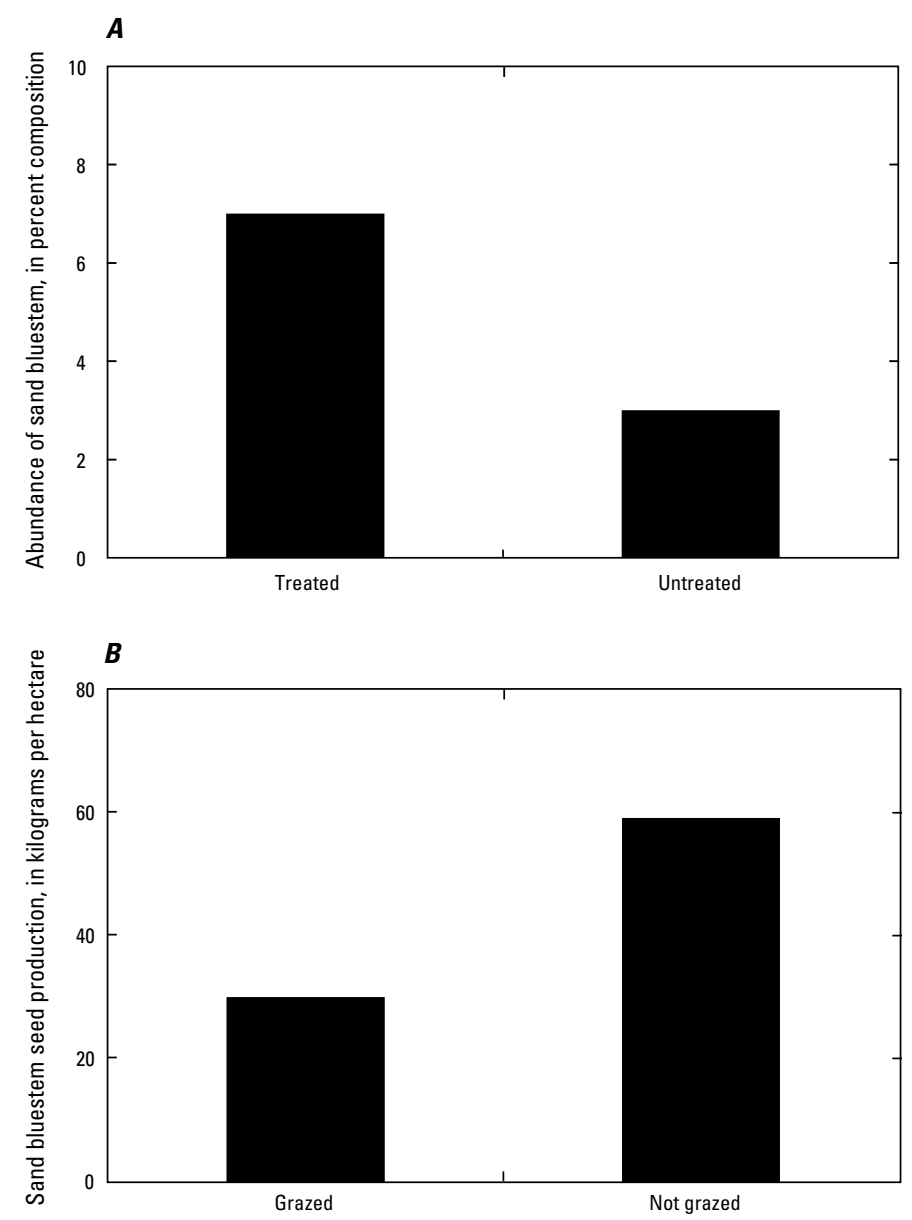

Figure 18. Abundance of sand bluestem, in terms of percent composition, as a dependent variable in models testing the effect of herbicide, $A$, and grazing treatments, $B$, in sand shinnery oak grass communities in Roosevelt County, New Mexico, 200210. The mean values for treated and not treated areas differed $(P<0.05)$. 


\section{Discussion}

\section{Microclimate and Thermal Stress}

We obtained thermal and RH data from the nests of 22 lesser prairie-chickens. This number was reduced from what was possible because of lack of nesting activity in 2011 and, presumably, very high temperatures early in the nesting season in 2012. Our hypothesis that nighttime nest temperatures would be greater than external temperatures was supported by the data, but we also anticipated that daytime nest temperatures would be cooler than external temperatures; however, nest temperatures were cooler only during the afternoon and midday hours when external temperatures were at their highest. In relation to ambient conditions, however, nest temperatures and $\mathrm{RH}$ remained relatively consistent. Indeed, it was quite noticeable on the ibutton data when hens took temporary leave of nests. These departures from the nest typically lasted for approximately $1 \mathrm{hr}$ and occurred at dawn and dusk (fig. 4). These data suggest that the presence of hens is critical in regulating the thermal and humidity conditions within nests.

Nests averaged $31.2^{\circ} \mathrm{C}$ with an average range of 28.5 $33.5^{\circ} \mathrm{C}$. The thermal tolerances of lesser prairie-chickens is as yet undetermined, but thermal tolerance for 80 percent survivorship among Galliformes eggs was estimated between 31 and $39^{\circ} \mathrm{C}$ (Webb, 1987); however, Webb (1987) suggested most species could survive a range of $36-39{ }^{\circ} \mathrm{C}$ for exposure of no more than a few hours. Based on our results, it appears that this range is applicable to lesser prairie-chickens. We witnessed ambient conditions approach this threshold for egg survival in 2011 and partially in 2012. Additionally, we witnessed multiple nest abandonments in 2009 when temperatures exceeded $37^{\circ} \mathrm{C}$ for 5 subsequent days in the last week of May. We witnessed three nest abandonments within 3 days of incubation initiation during 2011. On-ground temperatures from our dataloggers in 2011 revealed that temperatures around the nests exceeded $50^{\circ} \mathrm{C}$, which is well beyond the threshold for egg viability. Humidity may be an even greater issue for lesser prairie-chickens. Hermes (1995) recommended a relative humidity of 55-60 percent for captive incubation of bird eggs. Daytime humidity in our study area ranged between 10 percent (2011) and 35 percent (2010), but nest humidity averaged 56.8 percent, which is consistent with the recommendations of Hermes (1995). It appears that hens can maintain nests in an acceptable humidity under 2010 conditions; however, their ability to compensate for climate trends of hotter, drier air are limited on the basis of 2011 and 2012 results.

The use of cameras in this study was experimental, and the methods with which to optimize their use needed to be understood. We recorded 261 hours of video data at nests and were able to ascertain time spent on nest per day for hens and, in some cases, determine cause of nest failure. We cannot rule out the possibility that our nest-cameras caused some lesser prairie-chicken hens to abandon their nests or predisposed them to depredation in 2011 and 2012; however, these abandonments also occurred when surrounding nest vegetation was lacking because of drought in 2011 and unexpected treatment of tebuthiuron that occurred on one ranch in 2012. Interestingly, the two nests that we obtained footage from in 2012 were on a different ranch that was not treated with tebuthiuron. Patten and others (2005) suggested that areas treated with tebuthiuron can act as an ecological trap for nesting lesser prairie-chicken hens, and the nest abandonments we witnessed in 2012 could be due to hens abandoning their nests in response to repeated defoliation of surrounding vegetation.

The conflicting results we witnessed between 2010 and 2011-12 are interesting and warrant a few suggestions for placing cameras at lesser prairie-chicken nests. First, we suggest that investigators allow hens 1 full week of incubation before cameras are placed at nests to allow hens to become acclimated to their nesting environment. Secondly, we suggest that nest-cameras be placed between 1.5 and $3 \mathrm{~m}$ from the nest and be completely camouflaged by using surrounding vegetation and camouflaging materials. Third, it is prudent for investigators to avoid repeated visits to nests where cameras are installed. Lastly, there may be greater risk of disturbance and abandonment if cameras are installed during drought years or in years where potential nesting habitats have been altered by disturbance.

Camera data from this study were limited but interesting. In essence, we found that once a hen commenced gular flutter, she continued nonstop until the cooler temperatures of early evening. Flutter sequences ranged from 5 to 9 hours but on average were shorter in 2010 compared to 2011-12. These results suggest gular flutter was associated with ambient air temperature and relative humidity but may not necessarily be an indicator that the hen was experiencing thermal stress. We suspected that we overlooked another causative agent of this behavior, which may be exposure to direct solar radiation. Thus, in 2012 we used an LP02 pyranometer (Campbell Scientific, Logan, Utah, U.S.A.) to assess the potential effect of solar radiation on nesting lesser prairie-chickens. We deployed the pyranometer at each nest in 2012 immediately after the nest failed or hatched to avoid disturbing the nesting hen. Because of multiple nest failures and faulty ibutton readings, however, we were only able to use data from one nest. The pyranometer revealed that the nest provided little protection from solar radiation aside from 9 a.m. -2 p.m. because nest solar radiation was similar to outside solar radiation for the rest of the diurnal period. If thermal stress (as expressed by gular flutter) was explained by solar radiation, we would expect the hen to stop fluttering around 2 p.m. Instead, flutter lasted well into the evening and ended $\sim 8$ p.m. on average (figs. 19, 20). 


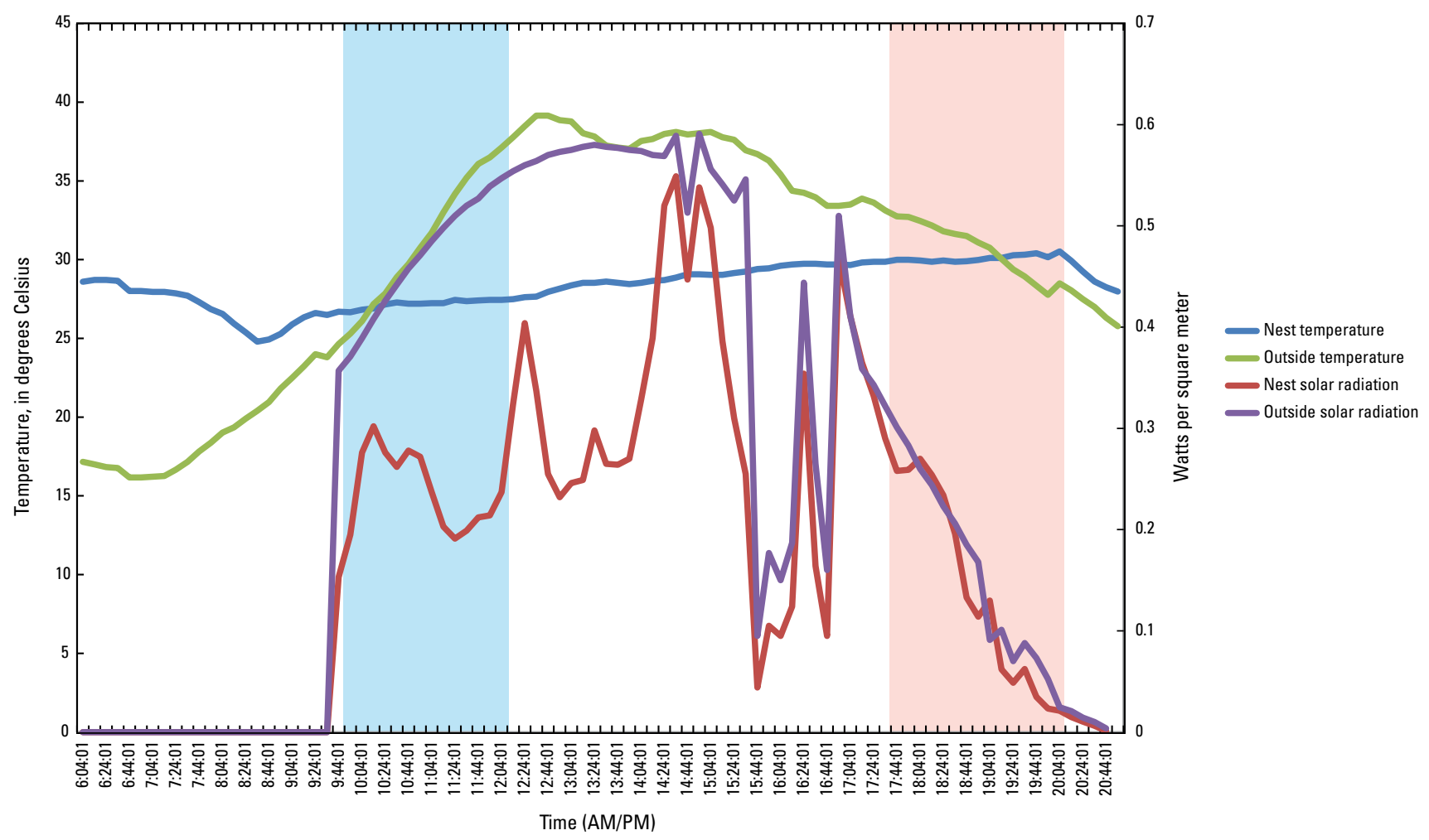

Figure 19. Nest and outside temperature and solar radiation for one nesting lesser prairie-chicken hen in 2012. Nest and outside temperature is the average value for each time interval for 10 days (May 15-25). Nest and outside solar radiation is the average value for each time interval for 3 days (May 26-29). The blue box represents the range of time intervals in which gular flutter started over the 10-day period, whereas the peach box represents the range of time intervals in which gular flutter ended over the 10-day period.

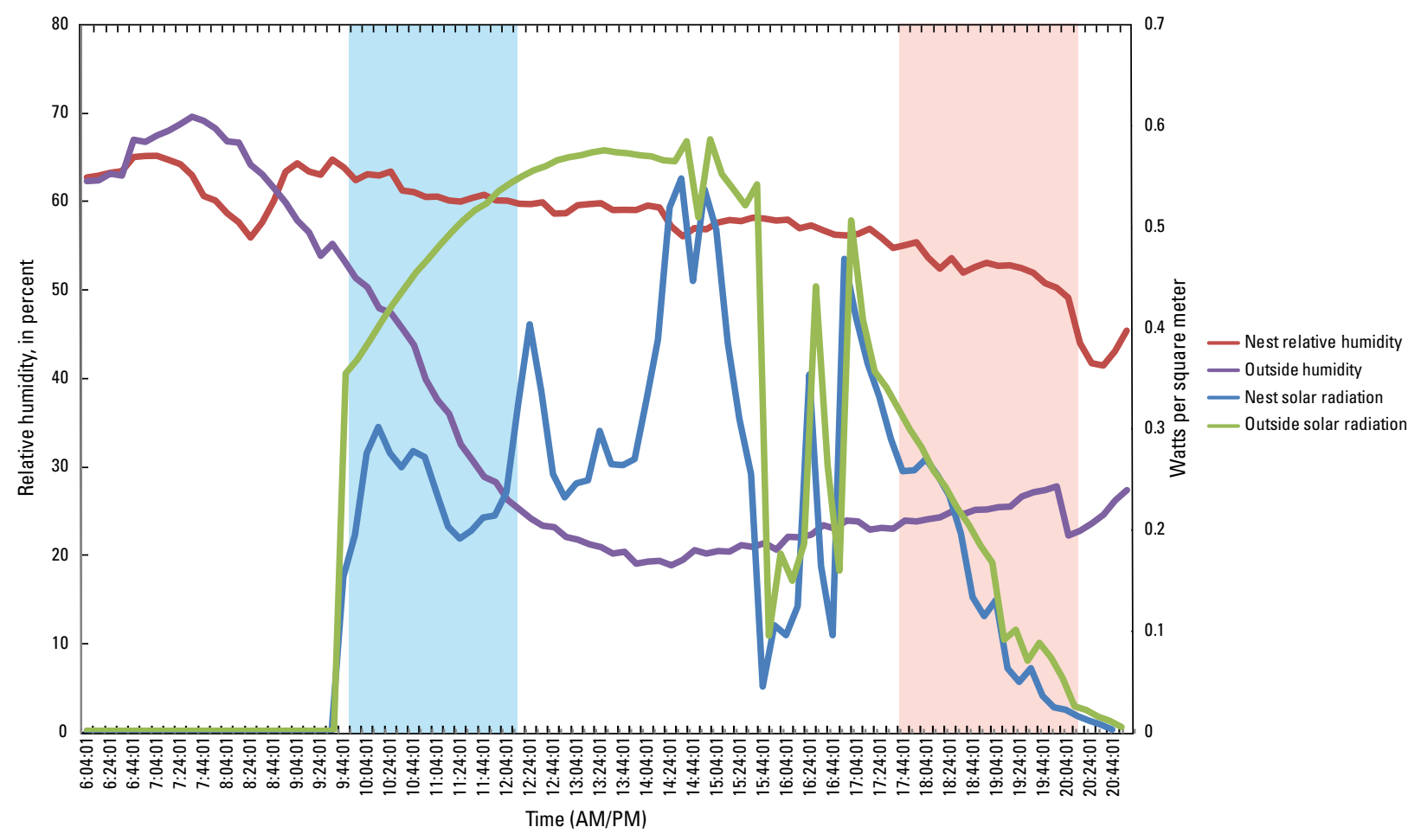

Figure 20. Nest and outside relative humidity and solar radiation for one nesting lesser prairie-chicken hen in 2012. Nest and outside relative humidity are the average value for each time interval for 10 days (May 15-25). Nest and outside solar radiation is the average value for each time interval for 3 days (May 26-29). The blue box represents the range of time intervals in which gular flutter started over the 10-day period, whereas the peach box represents the range of time intervals in which gular flutter ended over the 10-day period. 
The combined, limited results from all data sources (ibuttons, nest-cameras, pyranometer) suggest that gular flutter may not be an indicator of thermal stress. Another possible explanation is that it may be a physiological mechanism used to regulate nest humidity. Indeed, gular flutter sequences recorded in our analysis were shorter in 2010, when ambient conditions were cooler and more humid, compared to 201112 , when ambient conditions were hot and dry. Additionally, the one hen we recorded in 2012 tended to engage in gular flutter for longer periods of time on days when humidity was lower, regardless of solar exposure. Our observations are based on limited data, but we suggest they warrant continued investigation across the distribution of the lesser prairiechicken because of the climate change forecasts that predict hotter, drier springs on the Great Plains.

\section{Nesting Ecology}

Our assessment of nest-site selection and nest survival revealed several important aspects of lesser prairie-chicken nesting ecology in relation to herbicide and grazing treatments. First, nest density was not influenced by herbicide treatment. Second, there were no noticeable patterns of selection at the scale of individual lek, suggesting lesser prairie-chickens have the ability to adapt to surrounding habitat conditions, within the range of conditions suitable as suggested by Hagen and others (2004). Within this finding, nest survival was not different among treatments. Our results contrast significantly from Johnson and others (2004) and Haukos and Smith (1989), who found that nesting lesser prairie-chickens selected untreated pastures over treated pastures. We note two important differences between these studies and our results. First, the rate of herbicide application used in our study was less than that applied in these other two studies; vegetation composition is known to differ between pastures that are heavily treated and moderately treated (Peterson and Boyd, 1998; Haukos, 2011; Zavaleta, 2012). Second, the experimental design used for this study incorporated areas that were treated, not treated, grazed, and not grazed, which resulted in a heterogeneous landscape with an increasing diversity of plant communities and reduction in the amount of sand shinnery oak monocultures. Although lesser prairie-chickens nest in a wide variety of plant species, nest vegetation characteristics did not vary among treatments in 2001-5 or in 2006-10 (Grisham, 2012), suggesting that herbicide and short-duration grazing treatments may alter the community structure at larger scales (Zavaleta, 2012) but suitable nest vegetation remains within each type of treatment.

There was no noticeable selection pattern among the individual leks we assessed other than T-NG areas were used in proportion to what was expected. The inconsistencies occurred across four different patterns of treatment availability, and there was only one instance when the pattern of availability was the same (lek 1 vs. lek 17; table 11). In this case, NT-G areas were used less than expected, but the lack of this pattern among all leks suggested that nesting habitat remained in all treatment types specific to this study as well as a finer scale assessment of particular nest structure is warranted.

In addition, we did not detect differences in nest survival among treatments. These findings suggest that neither low-dose herbicide application nor light stocking rate nor combinations of these treatments are negatively influencing lesser prairie-chicken nest survival. The nest survival rate reported herein is consistent with, or lower than, other studies that have examined lesser prairie-chicken nest survival (Hagen and others, 2004; Fields and others, 2005; Pitman and others, 2006; Davis, 2009; Grisham, 2012). Data from Grisham (2012) and Fields and others (2005) suggest that nest vegetation is a poor predictor of nest survival. The survival estimates reported herein are only reflective of the candidate models within our assessment (treatment type assessment), and data from Grisham (2012) and Davis (2009) suggest other factors influence nest survival to a greater extent; therefore, nest survival in relation to nest vegetation structure may be low but may not translate to reduced productivity because of other underlying mechanisms not included in the candidate model set (that is, environmental conditions and vegetation interactions).

\section{Vegetation Response}

When a nearly monotypic sand shinnery oak site was treated with $0.60 \mathrm{~kg} / \mathrm{ha}$ of tebuthiuron, sand shinnery oak was reduced by 94 percent on sites that were not grazed, and 88 percent on sites that were grazed, throughout a 10 -year period. Moreover, when coupled with a grazing system that removes a maximum of 50 percent herbaceous production (25 percent removed at each grazing interval), sand shinnery oak did not increase in density following herbicide treatment (Zavaleta, 2012). Because sand shinnery oak is an effective water gatherer, controlling it to levels achieved in this study increased soil moisture, which then becomes available for other plants. Consistent with increased soil moisture, we noticed higher herbaceous biomass.

\section{Abiotic Factors}

Inouye (2005) found that the recharge of soil moisture was primarily the result of winter and early spring precipitation, with soil moisture declining during the spring and summer growing season as evaporation and transpiration increased. We found that the highest-ranking precipitation models for soil moisture in April and June included winter precipitation. Soil moisture increased by 16 and 17 percent in treated areas compared to untreated areas in April and July, respectively. This finding is consistent with other studies examining the influence of shrub removal on soil moisture. Inouye (2005) found that soil moisture was greater at depths of $120-180 \mathrm{~cm}$ in areas that had shrub removal in Idaho. Similar results have been found in semi-arid, shrub-grassland plant communities. In the Chaparral of California, brush control 
through the use of 2,4-D (a broadleaf herbicide), fire, and hand clearing was found to decrease soil moisture stress, which improved the chance of establishment of perennial grass (Test, 1972). Similarly, in Nevada, Robertson (1947) found that removal of big sagebrush increased available water for grass production.

Soil moisture dynamics affects not only overall biomass production but also plant communities. The limiting influence of soil moisture is accentuated in semiarid environments. For example, Pettit (1979) explained that sand shinnery oak does not require more water than grasses but is able to outcompete grasses in dry years because it starts spring growth 2 weeks earlier. The pattern of recharge and depletion of soil moisture favors plants that can quickly extract soil moisture early in the growing season (Inouye, 2005).

In periods of drought, sand shinnery oak has an advantage over grass because it stores up to 50 percent of its weight as water; however, when water is available, grasses can extract more deep soil water (Jones and Pettit, 1980). With the removal of sand shinnery oak, more water is available to support herbaceous production, which may mitigate grass loss during drought to a certain extent.

\section{Rates of Tebuthiuron}

It has been argued that herbicides, at a low rate, offer only temporary increases in herbaceous production and must be reapplied for 2-3 consecutive years (Scrifres, 1972; Pettit, 1979); this contention is not supported by our data. Our results show that when there is moderate grazing following herbicide treatment and period of rest subsequent to treatment, sand shinnery oak may not redevelop to pretreatment levels. This lack of redevelopment may be due to grasses remaining competitive under this grazing pressure. In fact, sand shinnery oak decreased by 88 and 94 percent in grazed areas and notgrazed areas, respectively, over 10 years.

Other research indicates that lower application rates $(<0.5$ $\mathrm{kg} / \mathrm{ha}$ ) of tebuthiuron can achieve a significant reduction in plant counts of sand shinnery oak. Jacoby and others (1983) found that mortality of sand shinnery oak, based on stem counts, was estimated at 42 and 94 percent with application rates of $0.5 \mathrm{~kg} / \mathrm{ha}$ and $1.0 \mathrm{~kg} / \mathrm{ha}$ rates of tebuthiuron, respectively, 18 months after treatment. Jones and Pettit (1980) found that at a rate of $0.4 \mathrm{~kg} / \mathrm{ha}$ sand shinnery oak was reduced by 95 percent after 3 years. This finding is consistent with our results, where, at a rate of $0.60 \mathrm{~kg} / \mathrm{ha}$, there was a significant herbicide effect on the reduction of sand shinnery oak in sand shinnery oak-grasslands in New Mexico.

We used the examples of sand shinnery oak and sand bluestem to illustrate the relation between shrub removal and grass growth. Both were significantly influenced by treatment. Sand shinnery oak was 91 percent less and sand bluestem was 118 percent more in treated areas as compared to untreated areas. It is reasonable to assume land managers could use comparable tebuthiuron rates to achieve historical standards of 15 percent of total shrub composition (USDA
NRCS, 2010; Zavaleta, 2012). For ecological restoration, the goal of treatment should not be to eliminate the sand shinnery oak completely in favor of grass production but rather to restore these communities to historical standards. Some land managers have recognized this paradigm shift and have reduced tebuthiuron application rates to less than $1.0 \mathrm{~kg} / \mathrm{ha}$ and deliberately avoided dune areas (Haukos, 2011).

\section{Changes in Composition}

Even at low doses, tebuthiuron treatment resulted in changes to the plant composition of the community on the sites examined in this study. There was a significant herbicide effect for the proportions of grass, shrub, forb, and litter, but not bare ground. Several studies have tested the effect of tebuthiuron on shrub control and grass production. Grass production and the types of grasses that grow will change depending on the rate of tebuthiuron and soil characteristics. Our results demonstrate that percent grass cover increased 149 percent in treated areas as compared to untreated areas. Jones and Pettit (1980) found the highest grass yield was four times greater at treatment rates of $0.8(\mathrm{~kg} / \mathrm{ha})$ compared to their control, but grass production increased 2.5 fold at a rate of $0.4 \mathrm{~kg} / \mathrm{ha}$. Doerr (1980) found that grass production increased 88-130 percent, with bunch grasses increasing 12-32 percent, when application rates were between 0.2 and $1.0 \mathrm{~kg} / \mathrm{ha}$.

Although our results suggested a positive relationship between grass production and tebuthiuron application, we stress that this relation is not linear. At application levels greater than $1.0 \mathrm{~kg} / \mathrm{ha}$, the increased benefit of grass production becomes null. At a rate of more than $3 \mathrm{~kg} / \mathrm{ha}$, nontarget grasses and forbs are killed. Jacoby and others (1983) reported that at a rate of $1.1 \mathrm{~kg} / \mathrm{ha}$ grass yields only doubled in treated as compared to untreated plots. Furthermore, it is important to note that the quality of grass production is also affected by high rates of tebuthiuron. At high application rates, most of the production results in annuals and undesirable plant species for cattle (Haukos, 2011).

Our results show that forb production is benefited by tebuthiuron treatment. Forbs increased nearly three-fold in treated areas as compared to untreated areas. Forbs generally increase in diversity and production 2 years after application (Doerr and Guthery, 1983; Haukos, 2011). Similar to grass production, there is a threshold in which tebuthiuron application is no longer beneficial. Doerr (1980) found that forb densities were decreased in plots with 0.8 and $1.0 \mathrm{~kg} / \mathrm{ha}$, and Scifres and Mutz (1978) found that most forb species were killed at application rates of 2.0 and $3.0 \mathrm{~kg} / \mathrm{ha}$.

Percent litter decreased by 17 percent in treated areas and 12 percent in grazed areas. Similarly, Sears and others (1986) found that litter decreased 32 percent in treated plots as compared to control six years after treatment. These changes are likely due to treated areas having more rooted herbaceous production so there is less litter compared to untreated areas. 
Tebuthiuron did not affect the amount of bare ground, but bare ground increased by 28 percent in grazed as compared to not-grazed treatments. Grazed areas are more likely to have bare ground because of herbaceous production removal by cattle. Our results differ from other studies where untreated plots contained almost twice as much bare ground as compared to treated plots (Jacoby and others, 1983). Differences in our results are likely due to the higher tebuthiuron application rate $(1.0 \mathrm{~kg} / \mathrm{ha})$ used by Jacoby and others (1983) compared to our study $(0.6 \mathrm{~kg} / \mathrm{ha})$ and may have been influenced by different precipitation patterns between study periods.

\section{Grazing}

In arid systems, livestock grazing can significantly alter soil properties and vegetative structure complexity (Castellano and Valone, 2006); however, the magnitude of these changes depends on the stocking rate and the level of grazing. In our study, grasses and forbs were able to persist because they remained a competitive part of the system. Litter and bare ground were the most affected by grazing with each increasing 13 percent and 28 percent, respectively. The increase in litter and bare ground provides more heterogeneity of the habitat, which may be beneficial for some types of rodents and herptiles (Zavaleta, 2012). Our results should be placed in context of the grazing system used for this assessment, including deferment of cattle 2 years after tebuthiuron application. Our results demonstrated that this lag period provided an opportunity for grasses and forbs to establish before grazing or herbaceous removal began.

\section{References Cited}

Anderson, D.R., Burnham, K.P., and Thompson, W.L., 2000, Null hypothesis testing-Problems, prevalence, and an alternative: Journal of Wildlife Management, v. 64, p. 912-923.

Boal, C.W., and Pirius, N.E., 2012,Winter ecology and habitat use of lesser prairie-chickens in west Texas, 2008-11: U.S. Geological Survey Open-File Report 2012-1073, 9 p.

Brown, D.P., and Comrie, A.C., 2002, Spatial modeling of winter temperature and precipitation in Arizona and New Mexico: Climate Research, v. 22, p. 115-128.

Castellano, M.J., and Valone, T.J., 2006, Effects of livestock removal and perennial grass recovery on the lizards of a desertified arid grassland: Journal of Arid Environments, v. 66, p. $87-95$.

Cochran, W.G., and Cox, G.M, 1957, Experimental designs: New York, N.Y., John Wiley and Sons, 640 p.
Copelin, F.F., 1963, The lesser prairie-chicken in Oklahoma: Oklahoma City, Okla., Oklahoma Department of Wildlife Technical Bulletin 6.

Corman, K.S., 2011, Conservation and landscape genetics of Texas lesser prairie-chicken-Population structure and differentiation, genetic variability, and effective size: Kingsville, Tex., Texas A\&M University-Kingsville, M.S. thesis, $181 \mathrm{p}$.

Crawford, J.A., and Bolen, E.G., 1975, Spring lek activity of the lesser prairie chicken in west Texas: The Auk, v. 92, p. $808-810$.

Crawford, J.A., 1980, Status, problem, and research needs of the lesser prairie chicken, in Vohs, P.A., and Knopf, F.L., eds., Proceedings Prairie Grouse Symposium: Stillwater, Okla., Oklahoma State University, p. 1-7.

Davis, Dawn, 2009, Nesting ecology and reproductive success of lesser prairie-chicken in shinnery oak dominated rangelands: The Wilson Journal of Ornithology, v. 121, p. 322-327.

Dawson, W.R., 1982, Evaporative losses of water by birds: Comparative Biochemistry Physiology, v. 71, p. 495-509.

Doerr, T.B., 1980, Effects of tebuthiuron on lesser prairiechicken habitat and foods supplies: Lubbock, Tex., Texas Tech University, M.S. thesis, 66 p.

Doerr, T.B., and Guthery, F.S., 1983, Effects of tebuthiuron on lesser prairie-chicken habitat and foods: Journal of Wildlife Management, v. 47, p. 1138-1142.

Fields, T.L., White, G.C., Gilgert, W.C., and Rodgers, R.D., 2005, Nest and brood survival of lesser prairie chickens in west central Kansas: Journal of Wildlife Management, v. 70, p. 931-938.

Giesen, K.M., 1998, Lesser prairie-chicken: The birds of North America 364, p. 1-17.

Grisham, B.A., 2012, The ecology of lesser prairie-chickens in shinnery oak-grassland communities of New Mexico and Texas with implications toward habitat management and climate change: Lubbock, Texas, Texas Tech University, Ph.D. dissertation, $320 \mathrm{p}$.

Hagen, C.A., Jamison, B.E., Giesen, K.M., and Riley, T.Z., 2004, Guidelines for managing lesser prairie-chicken populations and their habitats: Wildlife Society Bulletin 32, p. 69-82.

Hamerstrom, Frederick, and Hamerstrom, Frances, 1961, Status and problems of North American Grouse: Wilson Bulletin, v. 73, p. 284-294. 
Haukos, D.A., and Smith, L.M., 1989. Lesser prairiechicken nest site selection and vegetation characteristics in tebuthiuron-treated and untreated sand shinnery oak in Texas: Great Basin Naturalist, v. 49, p. 624-626.

Haukos, D.A., 2011, Use of tebuthiuron to restore sand shinnery oak grasslands of the Southern High Plains, in El-Ghany Hasanee, M.N., ed., Herbicides-Mechanisms and mode of action: Rijeka, Croatia, InTech Publishing, p. 103-124.

Heady, H.F., Gibbens, R.P., and Powell, R.W., 1959, A comparison of the charting line intercept, and line point methods of sampling shrub types of vegetation: Rangeland Management, v. 12, p. 180-188.

Hemes, J.C., 1995, Hatching small numbers of eggs: Pacific Northwest Cooperative Extension Service No. 478. U.S. Department of Agriculture.

Inouye, R.S., 2005, Effects of shrub removal and nitrogen addition on soil moisture in sagebrush steppe: Journal of Arid Environments, v. 65, p. 604-618.

Jacoby, P.W., Slosser, J.E., and Meadors, C.H., 1983, Vegetational responses following control of sand shinnery oak with tebuthiuron: Journal of Range Management, v. 36, p. 510-512.

Jones, V.E., and Pettit, R.D., 1980, Soil water in Graslan and untreated oak plots, in Research Highlights 1979 Noxious Brush and Weed Control—-Range, Wildlife, and Fisheries Management: Lubbock, Tex., Texas Tech University.

Johnson, Kristine, Smith, B.H., Sadoti, Giancarlo, Neville, T.B., and Neville, Paul, 2004. Habitat use and nest site selection by nesting lesser prairie-chickens in southeastern New Mexico: Southwestern Naturalist, v. 49, p. 334-343.

Karl, T.R., Melillo, J.M., and Peterson, T.C., 2009, Global climate change impacts in the United States: Cambridge, Mass., Cambridge University Press, 196 p.

Manly, B.F., McDonald, L.L., Thomas, D.L., McDonald, T.L., and Erickson, W.P., 2002, Resource selection by animalsStatistical design and analysis for field studies ( $2 \mathrm{~d}$ ed.): The Netherlands, Kluwer Academic Publishers, 221 p.

Merchant, S.S., 1982, Habitat use, reproductive success, and survival of female lesser prairie-chickens in two years of contrasting weather: Las Cruces, N. Mex., New Mexico State University, M.S. thesis, $72 \mathrm{p}$.

Newman, A.L., 1964, Soil survey of Cochran County, Texas: Washington, D.C., U.S. Department of Agriculture, Soil Conservation Service, 80 p. + maps.

Noy-Meir, Imanuel, 1973, Desert ecosystems-Environment and producers: Annual Review of Ecology and Systematics, v. 4 , p. $25-52$.
Olawsky, C.D., and Smith, L.M., 1991, Lesser prairie-chicken densities on tebuthiuron-treated and untreated sand shinnery oak rangelands: Journal of Range Management, v. 44, p. $364-368$.

Patten, M.A., Wolfe, D.H., Shochat, E., and Sherrod, S.K., 2005, Habitat fragmentation, rapid evolution, and population persistence: Evolutionary Research, v. 7, p. 235-249.

Peterson, R.S., and Boyd, C.S., 1998, Ecology and management of sand shinnery communities-A literature review: U.S. Forest Service, Rocky Mountain Research Station, General Technical Report RMRS-GTR, v. 16, p. 71-87.

Pettit, R.D., 1979, Effects of picloram and tebuthiuron pellets on sand shinnery oak communities: Journal of Range Management, v. 32, p. 196-200.

Pitman, J.C., Hagen, C.A., Jamison, B.E., Robel, R.J., Loughin, T.M., and Applegate, R.D., 2006, Nesting ecology of lesser prairie-chickens in sand sagebrush prairie of southwestern Kansas: Wilson Journal of Ornithology, v. 118 , p. 23-35.

Robertson, J.H., 1947, Responses of range grasses to different intensities of competition with sagebrush (Artemisia tridentate): Ecology, v. 48, p. 1034-1938.

Sala, O.W., and Lauenroth, W.K., 1982, Small rainfall events: An ecological role in semiarid regions: Oceologia, v. 53, p. 301-304.

Sears, W.E., Britton, C.M., Wester, D.B., and Pettit, R.D., 1986, Herbicide conversion of a sand shinnery oak community: Effects on Nitrogen: Journal of Range Management, v. 39, p. 403-407.

Scifres, C.J., 1972, Herbicide interactions in control of sand shinnery oak: Journal of Range Management, v. 24, p. 386-389.

Scifres, C.J., and Mutz, J.L., 1978, Herbaceous vegetation changes following applications of tebuthiuron for brush control: Society for Range Management, v. 31, p. 375-378.

Smythe, L.A., and Haukos, D.A., 2009, Nesting success of grassland birds in shinnery oak communities treated with tebuthiuron and grazing in Eastern New Mexico: The Southwestern Naturalist, v. 54, p. 136-145.

Strahan, R.T., 2008, A floristic survey of the vascular plants of the Milnesand Prairie Preserve, Roosevelt County, New Mexico: Las Cruces, N. Mex., New Mexico State University, M.S. thesis, 177 p.

Test, P.S., 1972, Soil moisture depletion and temperature affected by sand shinnery oak (Quercus havardii) control: Lubbock, Tex., Texas Tech University, M.S. thesis. 
USDA NRCS (United States Department of Agriculture, Natural Resources Conservation Service), 2011, Ecological site description for R077DY045TX: accessed August 16, 2011, at http://esis.sc.egov.usda.gov/esdreport/fsReport.aspx ?id=R077DY045TX\&rptLevel=all\&approved=yes.

U.S. Fish and Wildlife Service, 2011, Candidate and listing priority assignment form-Lesser prairie chicken: Tulsa, Okla., U.S. Fish and Wildlife Service.

Webb, D.R., 1987, Thermal tolerance of avian embryos-A review: The Condor, v. 89, p. 874-898.

WRCC (Western Region Climate Center), 2010, Period of record monthly climate summary from January 1, 1905 to January 31, 2012: accessed February 1, 2012, at http://www. wrcc.dri.edu/cgi-bin/cliMAIN.pl?nm7008.
Woodward, A.J.W., Fuhlendorf, S.D., Leslie, Jr., D.M., and Shackford, J., 2001, Influence of landscape composition and change on lesser prairie-chicken (Tympanuchus pallidicinctus) populations: The American Midland Naturalist, v. 145, p. 261-274.

Zar, J.H., 2010, Biostatistical analysis (5th edition): New Jersey, N.J., Upper Saddle River Press.

Zavaleta, J.C., 2012, Community response to use of prescribed grazing and herbicide for restoration of sand shinnery oak grasslands: Lubbock, Tex., Texas Tech University, M.S. thesis, $240 \mathrm{p}$. 


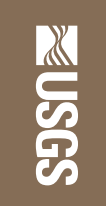

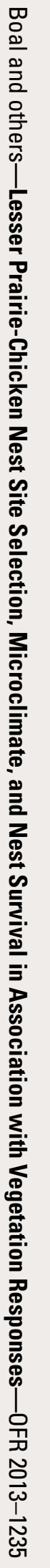

